\title{
Synthesis and Characterization of Phosphamacrocycles on the Basis of 2,7-Dihydroxynaphthalene
}

\author{
Pavel V. Slitikov, ${ }^{a}$ Yuliya B. Evdokimenkova ${ }^{\mathrm{b}}$ Elena N. Rasadkina $^{\mathrm{c}}$ \\ Larisa K. Vasyanina, ${ }^{\mathrm{c}}$ and Eduard E. Nifantiev ${ }^{\mathrm{c}}$ \\ ${ }^{a}$ Bauman Moscow State Technical University, 105005 Moscow, Russian Federation

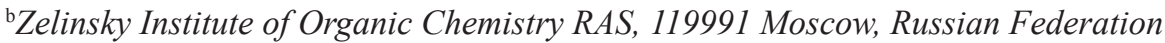 \\ 'Moscow Pedagogical State University, 119021 Moscow, Russian Federation \\ ${ }^{\circledR}$ Corresponding authorE-mail: pavlasiy@mail.ru
}

\begin{abstract}
Phosphorus containing macrocycles on the basis of 2,7-dihydroxynaphthalene and amides of phosphorous acid were synthesized. The molecular assembly technique for the preparation of "uniform" naphthaphosphacyclophanes (containing only residues of 2,7-dihydroxynaphtalene) and "nonuniform" naphthaphosphacyclophanes (containing different naphthylene residues with hydroxy groups located in different aromatic rings) is proposed. Their properties were studied and the computer MM2 optimizations of molecular geometry were carried out. A method for the preparation of phosphorus containing macrocycles with three or four regularly exchanging 2,7-dihydroxynaphtylene and phosphorus acid residues was proposed. Their oxidation and sulfur addition were also studied. Individual character and structure of all synthesized systems were proved unambiguously by $T L C,{ }^{31} \mathrm{P},{ }^{13} \mathrm{C}$ and ${ }^{1} \mathrm{H} N \mathrm{NR}$ spectroscopy, elemental analysis and MALDI-TOF mass-spectrometry.
\end{abstract}

Keywords: 2,7-Dihydroxynaphthalene, triamidophosphites, molecular assembly, macroheterocycles, naphthaphosphacyclophanes, phosphocrown ethers.

\section{Синтез и свойства фосфомакроциклических систем на основе 2,7-Аигидроксинафталина}

\author{
П. В. Слитиков, ${ }^{a} @$ Ю. Б. Евдокименкова, ${ }^{\mathrm{b}}$ Е. Н. Расадкина, ${ }^{\mathrm{c}}$ А. К. Васянина, ${ }^{\mathrm{c}}$ \\ Э. Е. Нифрантьев
}

\begin{abstract}
а Московский государственный технический университет им. Н.Э. Баумана, 105055 Москва, Россия
${ }^{\mathrm{b}}$ Институт органической химии им. Н.Д. Зелинского РАН, 119991 Москва, Россия

' Московский педагогический государственный университет, 119021 Москва, Россия

E-mail: pavlasiy@mail.ru
\end{abstract}

\begin{abstract}
В настоящей работе изучено фосфорилирование 2,7-дигидроксинафталина полными амидами фосфористой кислоты. Рассмотрены синтезы макроциклических систем, содержащих по два, три и четыре остатка 2,7дигидроксинафталина и остатков фосфорных кислот. Показана возможность синтеза «однородных» и «неоднородных» нафтофосфациклофанов. Исследованы некоторые структурные особенности синтезированных систем.
\end{abstract}

Ключевые слова: 2,7-Дигидроксинафталин, триамидофосфиты, молекулярная сборки, макрогетероциклы, нафтофосфациклофаны, фосфокраун-эфиры.

\section{Введение}

Одним из направлений современной элементорганической химии является развитие дизайна и изучение областей применения макроциклических систем. Среди их большого разнообразия особая роль отводится циклофанам - мостиковым макроциклическим системам, включающим ароматические и гетероаро- матические циклы, соединенные между собой алифатическими цепочками. ${ }^{[1,2]}$ Нафталиновые производные широко применяются в качестве ароматических блоков в циклофановых структурах..$^{[3-8]}$ Кроме того, сам нафталин и его производные (особенно гидроксипроизводные) являются хорошими акцепторами малых молекул, в частности, кислорода, ${ }^{[9-11]}$ удобными объектами для изучения процессов таутомерии, ${ }^{[12]}$ хорошо участвуют 
в образовании комплексов с переносом заряда. ${ }^{[13-16]}$ Введение в циклофаны гетероатомов, например, таких как фосфор, значительно расширяет круг их функционального использования. Такие макроциклические структуры могут принимать участие в регулировании динамики систем и усилении эффектов фосфорных групп, а также в самостоятельном лигандировании ионов металлов и образовании комплексов типа «гость-хозяин».

\section{Результаты и обсуждение}

В качестве объекта исследования нами был выбран доступный и удобный в работе симметричный 2,7-дигидроксинафталин (1), который применяется в создании искусственных рецепторов, ${ }^{[17-19]}$ используется в медицине и биохимии, ${ }^{[20,21]}$ а также в синтезе полимеров

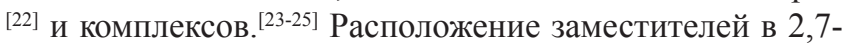
дигидроксинафталине делает возможным получение на его основе «двухступенчатых» фосфациклофанов, которые представляются особенно интересными соединениями в химическом отношении.

На первом этапе работы было изучено цикло(бисфосфорилирование) 2,7-дигидроксинафталина (1) триамидами фосфористой кислоты с различными заместителями у атома фосфора (2a-d), которые вступают во взаимодействие с фенолами уже при комнатной температуре в различных органических растворителях и не требуют удаления образующихся в процессе реакции вторичных аминов. ${ }^{[26]}$ В качестве растворителей были выбраны ацетонитрил, 1,4-диоксан, бензол, диэтиловый эфир. Было показано, что наилучшим растворителем в данном случае является ацетонитрил, так как фосфорилирование протекает в нем с наибольшей скоростью, не происходит образование побочных продуктов и, кроме того, образующиеся нафтофосфациклофаны отделяются из ацетонитрильного раствора, что в значительной степени облегчает их выделение.

Для получения указанных фосфоциклических систем были применены три препаративных метода: молекулярная сборка, прямое циклофосфорилирование и дисмутация бисфосфорилированных производных 2,7дигидроксинафталина. ${ }^{[27,28]}$

Первой стадией метода молекулярной сборки являлся синтез бисфосфорилированных нафтодиолов (3a-d).
При использовании динамических спектров ${ }^{31} \mathrm{P}$ ЯМР было показано, что время бисфосфорилирования варьируется от 6 мин (для диметиламидного реагента 3a) до 2 ч (для пиперидильного реагента 3d). Реакцию бисфосфорилирования считали прошедшей до конца, когда в спектре ${ }^{31} \mathrm{P}$ ЯМР исчезал сигнал в области $117-$ 122 м.д., характерной для полных амидов фосфористой кислоты 2a-d, и наблюдался только сигнал в области 127132 м.д., характерной для диамидоэфиров фосфористой кислоты с ароматическими заместителями 3a-d.

Bce синтезированные бисфосфорилированные продукты 3a-d являются неустойчивыми соединениями из-за склонности к дисмутации в растворах, поэтому для подтверждения их строения они были переведены в стабильные тионфосфаты (4a-d) и выделены методом колоночной хроматографии.

Бистионамидофосфаты 4a-d представляли собой кристаллические или маслообразные вещества. В их спектрах ${ }^{31} \mathrm{P}$ ЯМР наблюдались синглетные сигналы в области 68-78 м.д., характерной для арилдиамидотионфосфатов. Спектры ${ }^{1} \mathrm{H}$ ЯМР содержали сигналы всех групп протонов с соответствующим соотношением интегральных интенсивностей.

Строение молекулы соединения 4b было подтверждено рентгеноструктурным анализом (Рисунок 1), который показал, что молекула представляет собой изисконформер.

Заключительный этап синтеза - циклизация бисфосфорилированного соединения 3a-d исходным нафтодиолом 1 - приводил к образованию цикло(бисамидофосфитов) 5a-d, которые отделялись из реакционного ацетонитрильного раствора в виде вязких маслообразных веществ. После высушивания в вакууме они представляли собой хрупкие аморфные пенки или оставались маслообразными. Чем легче по массе радикал у атома азота, тем хуже растворимость соответствующих циклофосфитов 5a-d в ацетонитриле. Их индивидуальность и строение были доказаны методами ТCX, спектроскопии ЯМР ${ }^{1} \mathrm{H},{ }^{13} \mathrm{C}$ и ${ }^{31} \mathrm{P}$, а также элементным анализом и определением молекулярной массы методом MALDI-TOF.

Соединения 5a-d можно отнести к метациклофанам, для которых возможно существование син- и антиконформеров с взаимным переходом одного в другой.

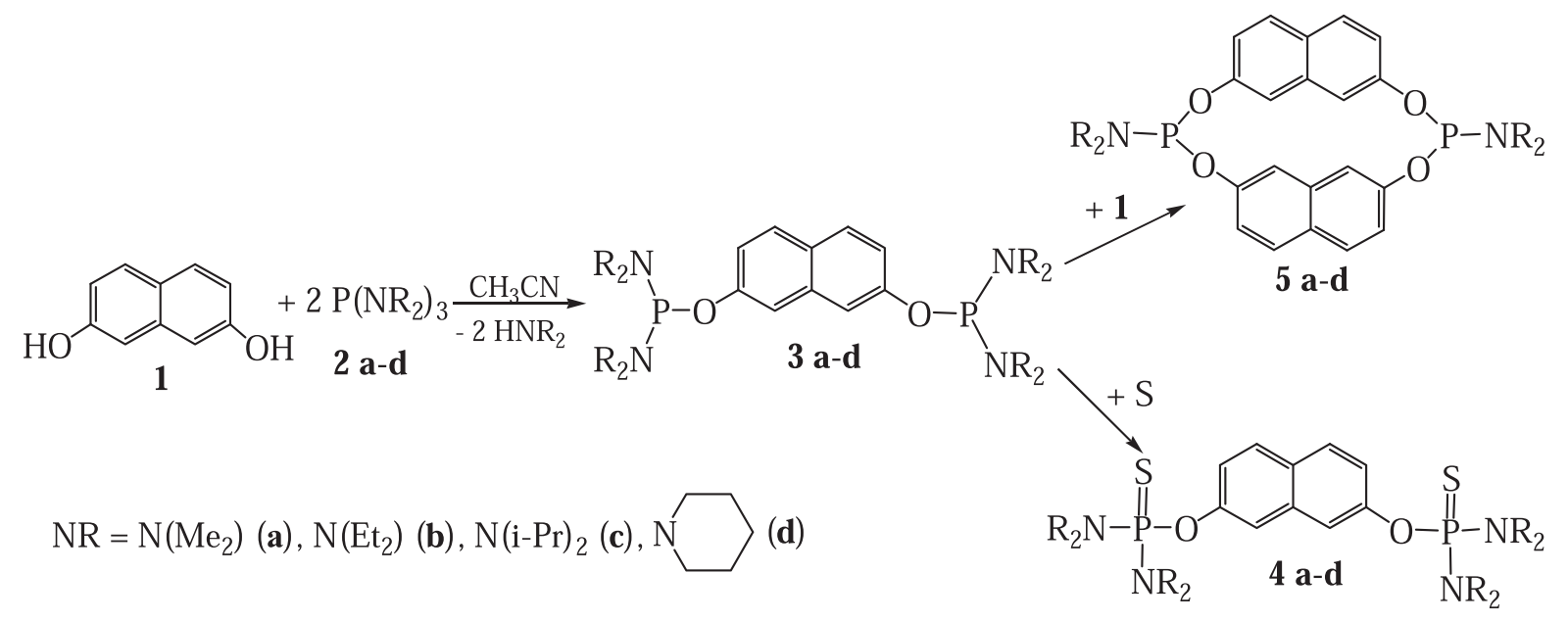




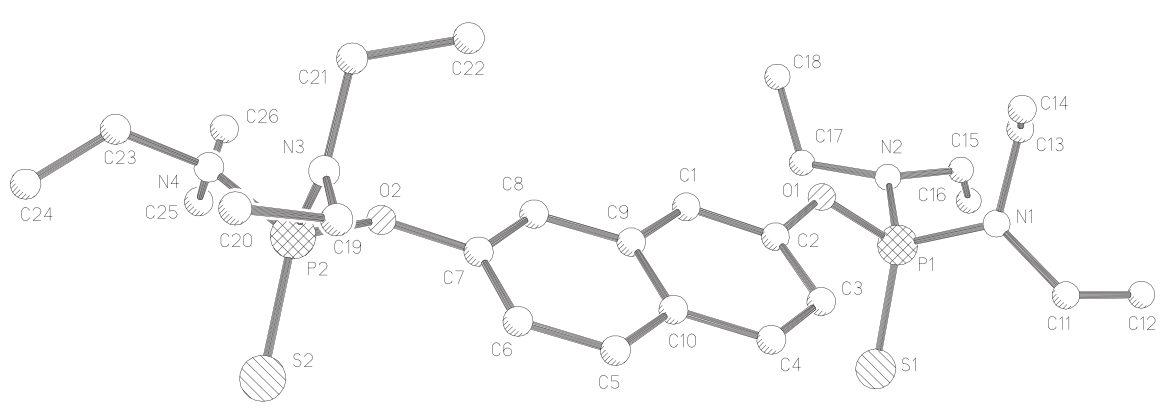

Рисунок 1. Молекулярная структура 2,7-бис(тетраэтилдиамидотионфосфатокси)нафталина (4b).

Наиболее близким по структуре к синтезированным нами нафтофосфациклофанам 5a-d является дитиа[3.3](2,7) нафтоциклофан, которыйв твердомсостоянииив растворе существует в виде син-конформера, а незначительное количество анти-конформера существует только при низких температурах. ${ }^{[3,4]}$ Это дает нам основание полагать, что полученные нами фосфоациклофаны 5a-d также являются син-конформерами.

Получить соединения $\mathbf{5 a - d}$ в кристаллической форме нам не удалось, что связано, согласно спектрам ${ }^{1} \mathrm{H}$ ЯМР, с наличием в их составе вторичных аминов, выделяющихся в процессе фосфорилирования и составляющих в среднем по данным спектров ${ }^{1} \mathrm{H}$ ЯМР и элементного анализа одну молекулу на 2-16 молекул циклофосфита 5a-d. Мы полагаем, что происходит образование устойчивого аддукта, стабилизующегося за счет неподеленной электронной пары азота и мощного ароматического блока нафталинового ядра, что не дает возможности нафтофосфациклофанам 5a-d кристаллизоваться.

Метод прямого синтеза основан на взаимодействии эквимолекулярных количеств исходных веществ. Было показано, что процесс прямого синтеза протекает через стадию монофосфорилирования с последующей конденсацией двух монофосфитов 6a-d в циклобисамидофосфит 5a-d.

Дисмутация ${ }^{[27,28]}$ бисфосфорилированных производных 2,7-дигидроксинафталина 3a-d, заключающаяся в их самопроизвольной циклизации с выделением полного амида фосфористой кислоты, также может использоваться для синтеза циклических систем. В общем виде процесс можно отразить схемой:

$$
2(\mathbf{3 a}-\mathbf{d}) \rightarrow \mathbf{5 a}-\mathbf{d}+2(\mathbf{2} \mathbf{a}-\mathbf{d})
$$

Дисмутация считается законченной, когда в спектре ${ }^{31} \mathrm{P}$ ЯМР исчезает сигнал в области соответствующей диамидоэфирам фосфористой кислоты 3a-d (127-132 м.д.) и накапливаются сигналы в области 138-141 м.д. (диэфироамиды фосфористой кислоты с ароматическими радикалами 5a-d) и 117-122 м.д. (полные амиды фосфористой кислоты 2a-d). Быстрее всего реакция протекает в дихлорметане, а медленнее - в 1,4-диоксане и бензоле. На скорость дисмутации оказывают влияние и заместители у атома фосфора. По скорости ухода при бисфософорилированиизаместителиможнорасположить в следующий ряд: метил - этил - изопропил - пиперидил. Однако при дисмутации заместители располагаются в обратном порядке.

Выход продуктов 5a-d был выше всего в методе прямого синтеза, а ниже всего - в случае дисмутации бисамидофосфитов 3a-d. Все физико-химические характеристики соединений, полученных по трем методам, были идентичны.

Метод молекулярной сборки позволяет получать не только «однородные» нафтофосфациклофаны, т.е. структуры, содержащие одинаковые нафтиленовые фрагменты, но и «неоднородные», содержащие два различных заместителя в бисциклической молекуле. Замена второго остатка 2,7-дигидроксинафталина 1 на другой ароматический фрагмент может привести к изменению конформации полученных циклических структур, а также к расширению их полости.

В связи с вышесказанным, мы синтезировали ряд «неоднородных» нафтофосфациклофанов на основе 2,7дигидроксинафталина и сравнили их свойства с «однородными» структурами. В качестве второго структурного блока для синтеза «неоднородных» фосфациклофанов были выбраны: дигидроксинафталины с различным расположением гидроксигрупп, два из которых являлись несимметричными (1,7- и 1,6-дигидроксинафталины) (7a,b), а два симметричными по различным осям (1,5и 2,6-дигидроксинафталины) (7c,d), а также 2,2-ди-nоксифенилпропан (ДИАН) (8) и 2,2'-дигидрокси-1,1'динафтилметан (9), представляющие собой ароматические диолы, содержащие гидроксогруппы в простран-

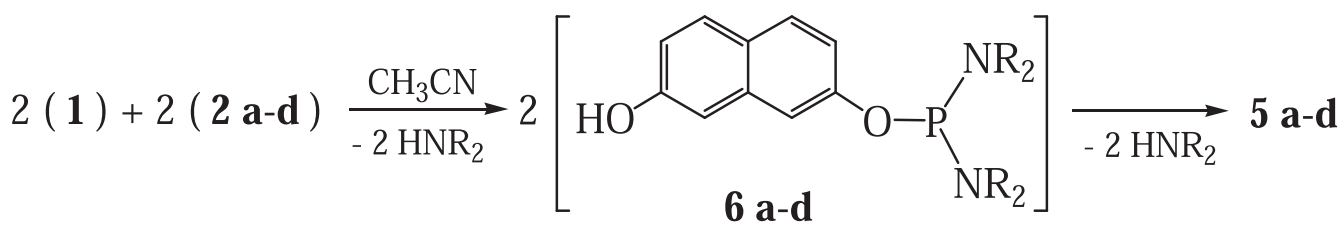


ственно удаленных ароматических ядрах. В качестве фосфорилирующего агента выбран гексаэтилтриамид фосфористой кислоты (ГЭТА) 2b, который имеет оптимальное время фосфорилирования для указанных ароматических систем.

Метод синтеза включал две стадии: получение бисфосфорилированных систем типа 3 и циклофосфорилирование этими соединениями двухосновных фенолов 1, 7a-d, 8, 9. В качестве растворителя был выбран ацетонитрил, так как конечные продукты в нем практически не растворимы. Заметим, что в данном случае ключевое значение имеет время полного бисфосфори-

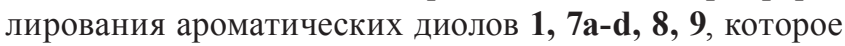
было определено по данным спектров ${ }^{31} \mathrm{P}$ ЯМР реакционных смесей (Таблица 1). Необходимость учета временного режима связана со склонностью бисфосфорилированных дигидроксинафталинов 3a-d, являющихся лабильными соединениями, легко вступать в дисмутацию с образованием однородных циклических систем, которые могут загрязнять целевые продукты. В связи с вышесказанным, из двух ароматических диолов, образующих «неоднородный» фосфациклофан, бисфосфорилированию подвергался тот, которому на данный процесс требовалось большее время.

Таблица 1. Время бисфосфорилирования (мин) ароматических диолов 1, 7a-d, 8, 9 ГЭТА (2b) в ацетонитриле.

\begin{tabular}{cc}
\hline Диол & Время, мин \\
\hline 2,7-Дигидроксинафтали $\mathbf{1}$ & 15 \\
1,7-Дигидроксинафталин 7a & 25 \\
1,6-Дигидроксинафталин 7b & 60 \\
1,5-Дигидроксинафталин 7c & 30 \\
2,6-Дигидроксинафталин 7d & 15 \\
2,2-Ди-n-оксифенилпропан 8 & 120 \\
2,2'-Дигидрокси-1,1'-динафтилметан 9 & $-*$ \\
\hline
\end{tabular}

*2,2'-дигидрокси-1,1'-динафтилметан 9 не образует бисфосфорилированных систем. ${ }^{[29,30]}$

В ходе реакции бисфосфорилирования в спектрах ${ }^{31} \mathrm{P}$ ЯМР наблюдалось исчезновение сигнала ГЭТА $\mathbf{2 b}$ (118.2 м.д.) и накопление сигнала диамидоэфира фосфористой кислоты 3b, 10-13 в области 132 м.д. За время, необходимое для полного завершения первой стадии, процесс дисмутации себя не проявляет. На второй стадии циклофосфорилирование завершалось за 48 ч при комнатной температуре, при этом образующиеся в результате реакции «неоднородные» фосфациклофаны 14-19 отделялись из раствора в виде масел. После высушивания в вакууме фосфациклофаны 14-19 представляли собой либо маслообразные продукты, либо легкоплавкие порошки, хорошо растворимые в дихлорметане, бензоле, 1,4-диоксане и диэтиловом эфире. Их выходы составляли $\sim 75 \%$. В спектрах ${ }^{31} \mathrm{P}$ ЯМР соединений 14-19 наблюдались сигналы в области 140 м.д., что соответствует области диэфироамидов фосфористой кислоты с ароматическими заместителями.

Интересной особенность производного 14 на основе 1,7-дигидроксинафталина является уширение всех сигналов протонов в спектрах ${ }^{1} \mathrm{H}$ ЯМР, чего не наблюдается у его «однородного» аналога. ${ }^{[31]}$ Замена растворителя, изменение температуры и увеличение чувствительности спектрометра с 200 до 500 МГц не приводит к увеличению разрешения сигналов. Мы полагаем, что это связано со структурой самой молекулы, а точнее, с наличием частично заторможенных конформаций. Спектр ${ }^{13} \mathrm{C}$ ЯМР соединения 14 соответствовал указанной структуре.

Отличительной особенностью производных на основе $1,5-$ и 2,6-дигидроксинафталинов $(\mathbf{1 6}, \mathbf{1 7})$ является то, что в спектрах ${ }^{1} \mathrm{H}$ ЯМР сигналы протонов ароматической части макроциклической молекулы не меняют химических сдвигов при замене второго нафтильного фрагмента молекулы, тогда как для аналогичных соединений на основе остальных ароматических диолов такое изменение наблюдается. Это может быть связано с тем, что данные нафтильные радикалы, являющиеся симметричными, в силу своих структурных особенностей образуют макроциклы, имеющие большее число степеней свободы для конформационных переходов.

При нахождении в растворе «неоднородный» фосфациклофан 19 на основе 2,2'-дигидрокси-1,1'динафтилметана 9 претерпевает симметризацию, т.е. распадается, образуя при этом «однородный» нафтофосфациклофан 5b и 1,3,2-диоксафосфацин 20 :

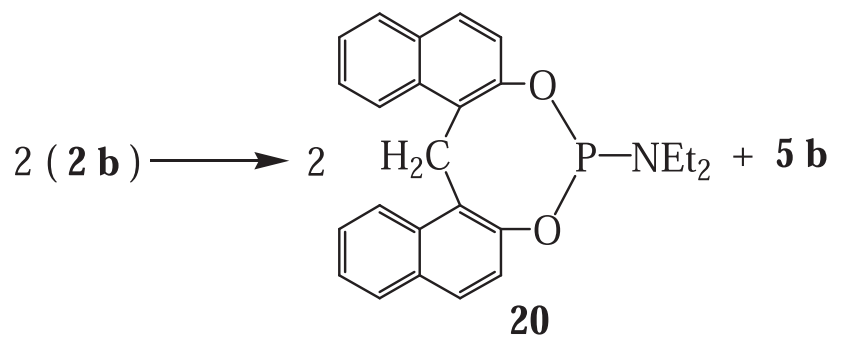

Симметризация быстрее всего протекает в дихлорметане, медленнее всего - в 1,4-диоксане. Строение и индивидуальность соединений $\mathbf{5 b}$ и 20 была подтверждена физико-химическими методами $\left({ }^{1} \mathrm{H},{ }^{31} \mathrm{P}\right.$ ЯМР и TCX). Характеристики полученных циклофосфитов $\mathbf{5 b}$ и 20 полностью совпадали с полученными ранее. ${ }^{[29,30]}$

Следует отметить, что другие «неоднородные» фосфациклофаны 14-19 не подвержены такой симметризации даже при очень длительном стоянии в растворе. Тем не менее в литературе имеются сведения о симметризации «неоднородных» циклофосфитов на основе 2,2-ди- $n$-оксифенилпропана 8. ${ }^{[32]}$

Для дополнительной идентификации полученных конструкций 5a-d, 14-19 были проведены их окисление и сульфуризация.

Сульфуризация проходила при комнатной температуре в дихлорметане за 1 сут. Полученные циклоамидотиофосфаты 21a-d, 22-27 выделяли методом колоночной хроматографии. Они представляли собой маслообразные вещества или легкоплавкие порошки. В их спектрах ${ }^{31} \mathrm{P}$ ЯМР наблюдались сигналы в области 66 м.д., характерные для цикло(амидотионфосфатов). Следует отметить, что производные 21с и 21d подвергались при хроматографическом выделении полной деструкции.

Окисление проводили комплексом мочевины с пероксидом водорода. Реакция протекала при комнатной температуре в дихлорметане за 1 сут. Полученные 


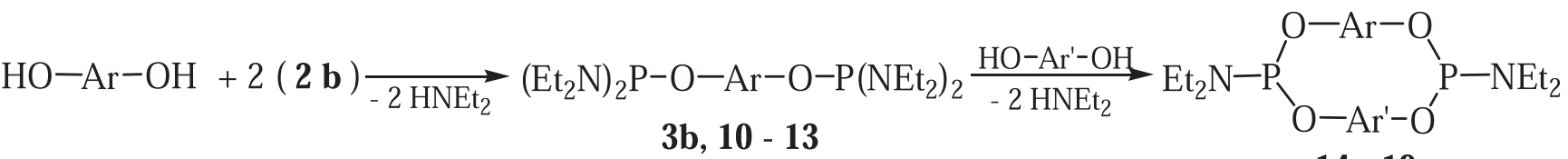

$$
\begin{aligned}
& 14 \text { - } 19
\end{aligned}
$$

№ бисфосфорилированного
продукта

фосфаты 28a-d, 29-34 были выделены методом переосаждения и представляли собой порошкообразные вещества. В их спектрах ${ }^{31} \mathrm{P}$ ЯМР наблюдались сигналы в области 1 м.д., характерной для моноамидофосфатов.

Изменение конфигурации фосфорного узла не влияет на разрешение сигналов в спектрах ${ }^{1} \mathrm{H}$ ЯМР для производных 22 и 29 на основе 1,7-дигидроксинафталина. Сигналы остаются уширеными при повышенной температуре и увеличении частоты регистрации спектров. Строение соответствующих амидофосфатов 22 и 29 доказано методом ${ }^{13} \mathrm{C}$ ЯМР. Также уширение сигналов протонов ароматической части наблюдается у тионфосфатов 26 и 27 на основе ДИАНа и 2,2'дигидрокси-1,1'-динафтилметана соответственно, тогда как у их кислородсодержащих аналогов 33 и 34 такое уширение отсутствует. Мы полагаем, что это связано с влиянием более объемного атома серы, изменяющего конфигурацию фосфорного узла и приводящего к образованию заторможенных конформаций.

Для молекул тионфосфата 26, как имеющего самую большую полость из всех представленных нафтофосфоциклофанов, было проведено исследование по измерению парциальных мольных объемов в метиленхлориде и диоксане. Рассчитанные значения собственных (ван-дер-ваальсовых) объемов этих молекул показали наличие внутримолекулярной полости, в которую не могут поместится ни молекулы диэтиламина, ни молекулы растворителей, использованных в синтезе. Однако, в спектрах ${ }^{1} \mathrm{H}$ ЯМР, даже после глубоковакуумной осушке вещества 26, наблюдаются сигналы диэтиламина и диоксана. По нашему мнению, это свидетельствует об образовании довольно прочных межмолекулярных нековалентных связей вне полости макроцикла.

Эксперимент показал, что синтезированные циклофосфаты 28a-d, 29-34, а особенно циклотионфосфаты 21a-d, 22-27, являются менее устойчивыми системами, чем соответствующие циклофосфиты 5a-d, 14-19. Мы полагаем, что это связано с факторами изменения делокализации электронной плотности фосфорного узла и геометрии циклической молекулы в целом при переходе фосфора из трехвалентного в пятивалентное состояние. Это подтвердили и компьютерные расчеты по оптимизации геометрии молекул и их стерических энергий в газовой фазе с использованием метода $\mathrm{MM}{ }^{[33]}$ для циклофосфитов 5a-d, 14-19, циклотионфосфатов 21a-d, 
Phosphamacrocycles on the Basis of 2,7-Dihydroxynaphthalene

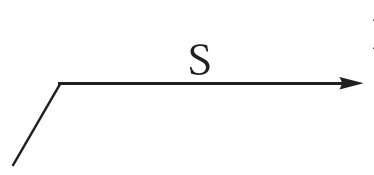

5 a-d, 14 - 19

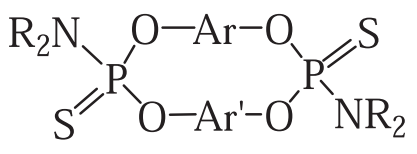

21 a-d, 22 - 27<smiles>Cc1ccc2ccc(C)cc2c1</smiles><smiles>NC(=O)CCCC(=O)O</smiles>
$-\mathrm{CO}\left(\mathrm{NH}_{2}\right)_{2} \cdot \mathrm{H}_{2} \mathrm{O}$

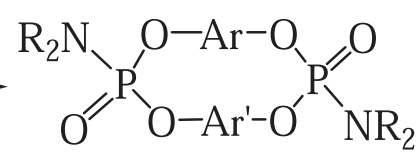

28 a-d, 29 - 34

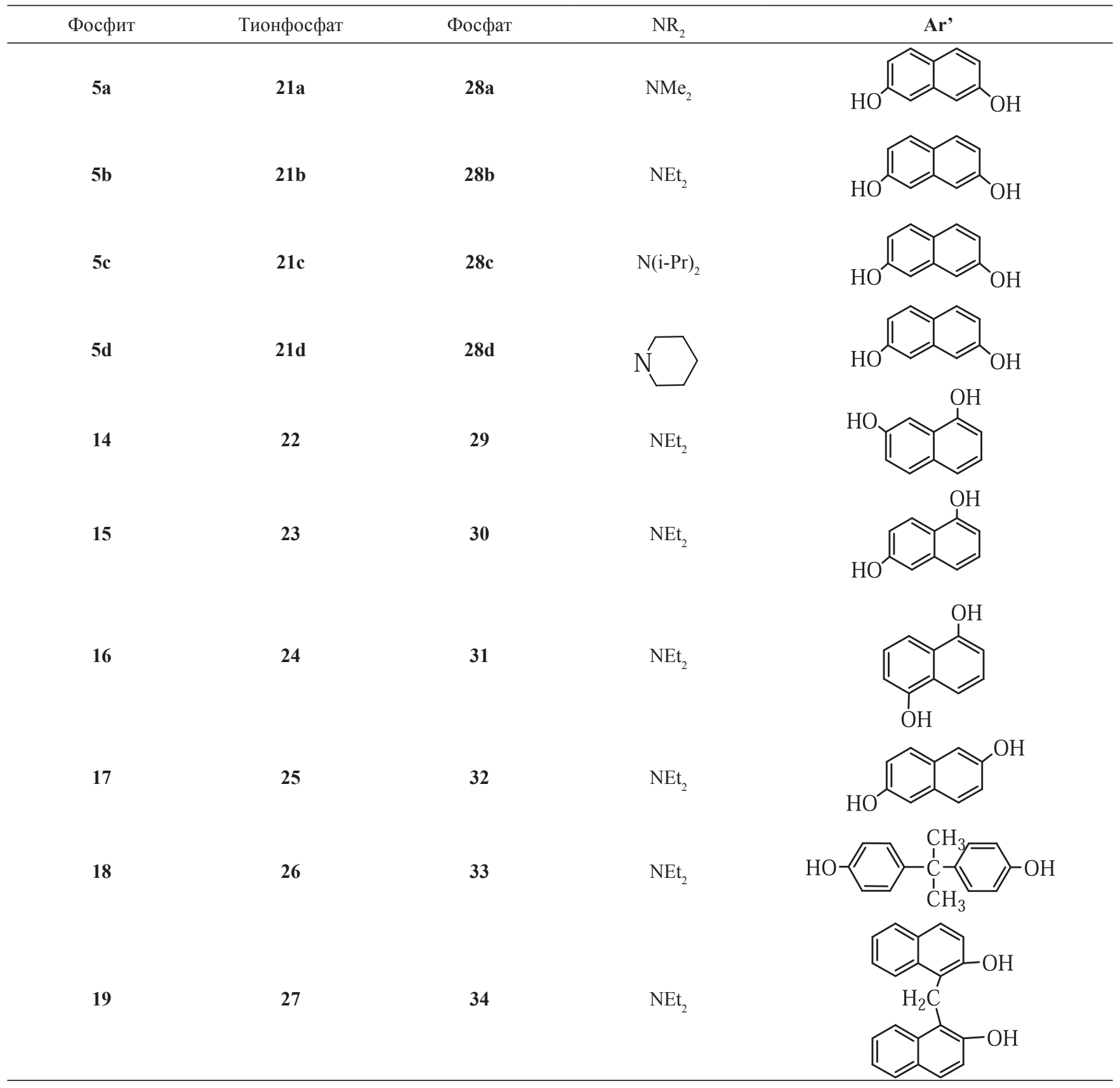

22-27 и циклофосфатов 28a-d, 29-34. Было показано, что стерическая энергия циклофосфитов меньше энергии соответствующих тион- и оксопроизводных более чем в два раза (Таблица 2).

На втором этапе нашей работы была поставлена задача осуществить синтез родственных макроциклических конструкций, обладающих большим объемом молекулярной полости, т.е. содержащих три или четыре остатка 2,7-дигидроксинафталина 1 и амидов фосфористой кислоты. При этом мы использовали наш опыт по дизайну аналогичных, но более простых макроциклов, полученных на основе резорцина и 
Таблица 2. Сравнение стерических энергий (эВ) фосфитов (5a-d, 14-19), тионфосфатов (21a-d, 22-27) и фосфатов (28a-d, 29-34).

\begin{tabular}{|c|c|c|c|c|c|c|c|}
\hline \multicolumn{6}{|c|}{$E_{\text {стер }}$} & \multirow{3}{*}{$E_{2}-E_{1}$} & \multirow{3}{*}{$E_{2}-E_{3}$} \\
\hline \multicolumn{2}{|c|}{ Фосфиты } & \multicolumn{2}{|c|}{ Тионфосфаты } & \multicolumn{2}{|c|}{ Фосфаты } & & \\
\hline № & $E_{1}$ & № & $E_{2}$ & № & $E_{3}$ & & \\
\hline 5a & 24.1 & 21a & 50.8 & $28 \mathrm{a}$ & 51.5 & 26.7 & -0.7 \\
\hline $5 \mathbf{b}$ & 11.8 & $21 b$ & 51.3 & $28 b$ & 49.9 & 39.5 & 1.4 \\
\hline $5 c$ & 35.2 & $21 \mathrm{c}$ & 64.0 & $28 \mathrm{c}$ & 58.6 & 28.8 & 5.4 \\
\hline $5 d$ & 20.9 & 21d & 67.0 & $28 d$ & 67.6 & 46.1 & -0.6 \\
\hline 14 & 19.2 & 22 & 59.9 & 29 & 52.8 & 40.7 & 7.1 \\
\hline 15 & 18.9 & 23 & 53.5 & 30 & 52.7 & 34.5 & 0.8 \\
\hline 16 & 27.5 & 24 & 56.2 & 31 & 53.8 & 31.8 & 2.4 \\
\hline 17 & 24.4 & 25 & 53.4 & 32 & 51.5 & 33.2 & 1.9 \\
\hline 18 & 17.0 & 26 & 51.0 & 33 & 49.8 & 34.0 & 1.2 \\
\hline 19 & 15.7 & 27 & 43.1 & 34 & 44.2 & 27.4 & -1.1 \\
\hline
\end{tabular}

гексаалкилтриамидов фосфористой кислоты, которые можно отнести к классу фосфобензокраун-эфиров. ${ }^{[34-36]}$

Первоначально макроциклы, содержащие по три остатка нафталиновых и фосфорных фрагмента, мы предполагали получать методом молекулярной сборки, заключающимся в последовательном связывании нафтильных и амидофосфитных фрагментов. Однако этот план оказался затруднительным, так как используемые полупродукты - линейные олигонафтиленамидофосфиты - проявляют склонность к самоциклизации, приводящей к образованию циклобисамидофосфитов 5a-d. Поэтому мы модернизировали схему синтеза и для повышения устойчивости линейных полупродуктов ввели процедуру перевода их в тионфосфаты.

С этим дополнением мы осуществили два варианта сборки искомых систем, в молекулах которых содержатся амидофосфитные и тионамидофосфатные функции.

Первый вариант предполагал использование бисамидофосфита $\mathbf{3 b}$, который вводился в реакцию с 2,7дигидроксинафталином 1, что приводило к образованию соединение 35 , которое сразу же стабилизировалось в виде дитионфосфата 36. Отметим, что искомый продукт 35 практически полностью образуется только при избытке диола 1. При использовании эквимолекулрных количеств реагентов основным продуктом является бисциклоамидофосфит $\mathbf{5 b}$. Для получения линейного олигомера 35, содержащего три ароматических центра, был использован только ГЭТА $\mathbf{2 b}$, т.к. использование других триамидов фосфористой кислоты приводило либо к очень быстрой дисмутации и не давало возможности препаративно перевести его в тионфосфат 36, либо к образованию побочных продуктов фосфорилирования. В качестве растворителя был использован ацетонитрил.

Сульфуризация продукта $\mathbf{3 5}$ протекала в ацетонитриле за 2 сут. Дитионамидофосфат 36 был выделен методом колоночной хроматографии и представлял собой маслообразноевещество. Вего спектре ${ }^{31} \mathrm{P}$ ЯМР фиксировали единственный синглетный сигнал с $\delta=67.3$ м.д., характерный для моноамидодиэфиров тионфосфорной кислоты. В спектре ${ }^{1} \mathrm{H}$ ЯМР имели место сигналы всех групп протонов, в том числе и сигнал протонов двух гидроксильных групп с соответствующим соотношением интегральных интенсивностей.

Далее была проведена фосфоциклизация дитионамидофосфата 36 молем гексаалкилтриамидов фосфористой кислоты 2 a,b.

Полученные соединения 37a,b представляли собой вязкие масла. В их спектрах ${ }^{31} \mathrm{P}$ ЯМР наблюдалось по два синглетных сигнала с $\delta=139.7$ и 66.7 м.д. (37a) и $\delta$ $=140.7$ и 66.7 м.д. (37b) с соотношением интегральных интенсивностей $1: 2$ соответственно. Полученные продукты 37a,b при стоянии в растворе легко подвергаются перегруппировке с образованием циклобисамидофосфатов 5a,b, поэтому для их стабилизации была проведена сульфуризация. После выделения методом колоночной хроматографии тионфосфаты 38a,b являются низкоплавкими порошками. В спектре ${ }^{31} \mathrm{P}$ ЯМР метильного производного 38а имеет место два синглетных сигнала

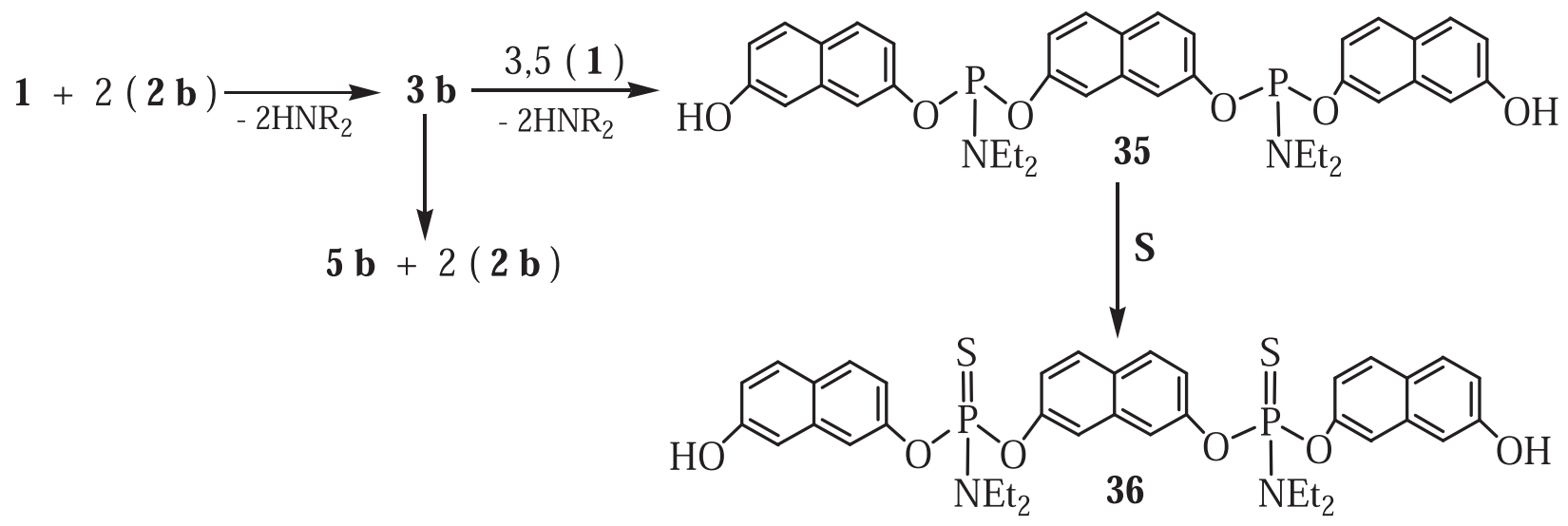




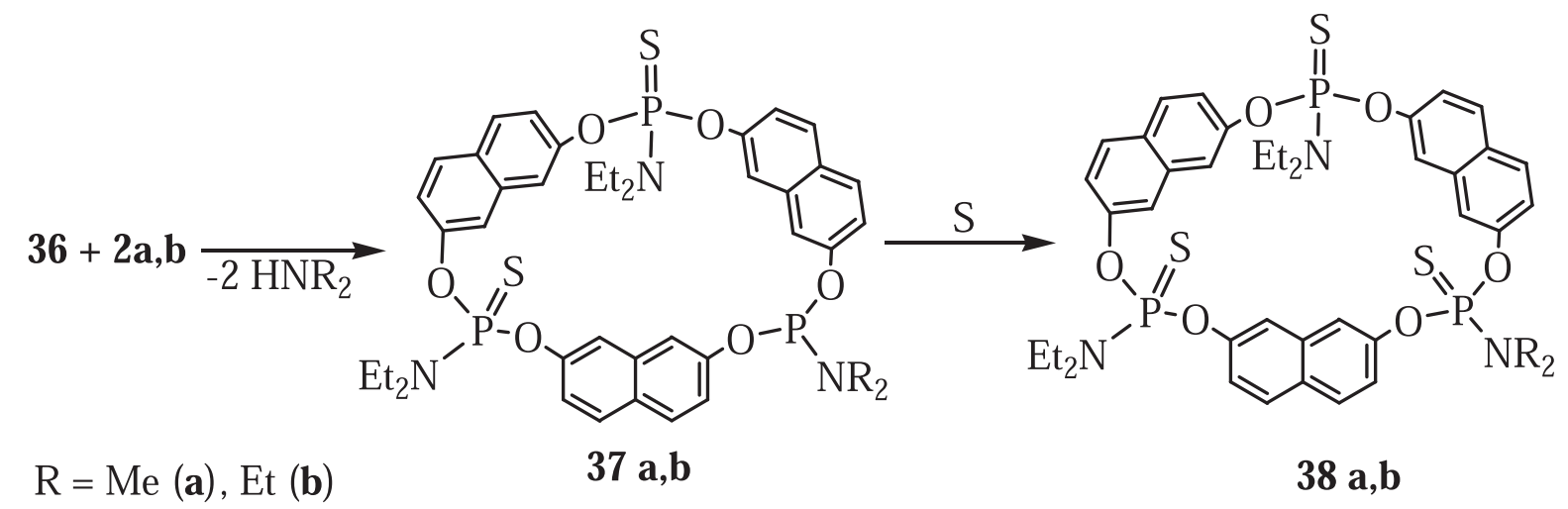

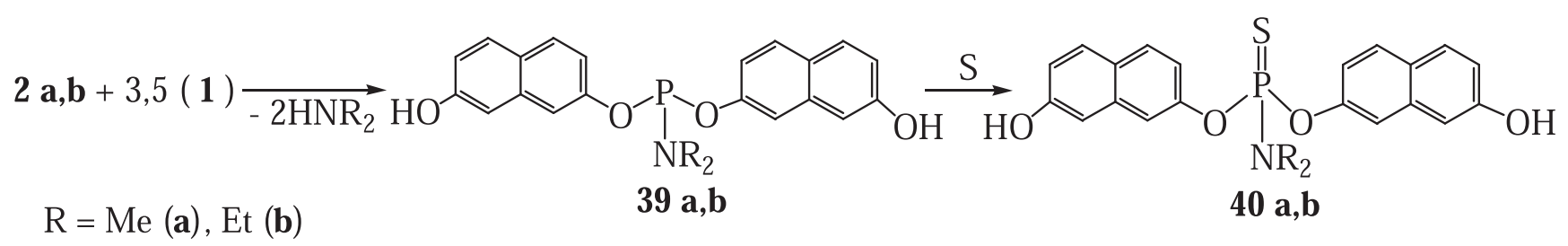

с $\delta=68.1$ и 66.7 м.д. с соотношением интегральных интенсивностей $1: 2$ соответственно, а в случае этильного производного $\mathbf{3 8 b}$ - один синглетный сигнал с $\delta=66.7$ м.д., характерные для амидотионфосфатов. Следует отметить, что мы наблюдали интересный факт при изучении спектров ${ }^{1} \mathrm{H}$ ЯМР: если в системе содержатся различные алкильные заместители у атомов азота, то имеет место неэквивалентность всех групп протонов, тогда как в случае одинаковых радикалов такая неэквивалентность отсутствует.

Второй метод предполагал синтез бис(нафтиленамидов) фосфористой кислоты 39a,b c последующей их фосфоциклизацией бисамидофосфитом $\mathbf{3 b}$.

Было показано, что использование избытка 2,7дигидроксинафталина 1 при проведении данной реакции полностью исключает образование циклического продукта 5a,b. Так как хроматографическое выделение соединений 39a,b приводит к резкому снижению выхода, что препятствует их дальнейшему использованию, неочищенные биснафтиленамидофосфиты 39a,b были переведены в тионфосфаты 40a,b.

Для дальнейшей циклизации к бисфосфорилированному продукту $\mathbf{3 b}$ добавляли синтезированные тионфосфаты 40a,b.

В результате из реакционного раствора отделялись маслообразные вещества, хорошо растворимые в дихлорметане и 1,4-диоксане. В спектре ${ }^{31} \mathrm{P}$ ЯМР полученных соединений 41 a,b наблюдались сигналы от двух типов фосфорных узлов: $\delta=68.2$ и 140.9 м.д. (41a) и $\delta=66.9$ и 140.9 м.д. (41b) с соотношением интегральных интенсивностей $1: 2$. После сульфуризации реакционной смеси выделенные колоночной хроматографией продукты оказались полностью идентичны соединениям 38a,b.

Необходимо отметить, что новые молекулярные полости 38a,b проявляют стремление к образованию соединений включения. На это указывает тот факт, что даже после длительного высушивания образцов в вакууме $\left(60^{\circ} \mathrm{C}, 1 \mathrm{Topp}\right)$ в их спектрах ${ }^{1} \mathrm{H}$ ЯМР наблюдались сигналы соответствующих аминов, выделяющихся в процессе реакции, а также используемых растворителей, в том числе метиленхлорида.

Сравнивая макроциклы 38a,b c аналогичными системами на основе резорцина, ${ }^{[34-36]}$ можно отметить, что 2,7-дигидроксинафталин в подобном синтезе ведет себя отлично от резорцина. Устойчивые трис(ариленфосфоцикланы) в этом случае можно получить только либо со смешанными фосфорными функциями, либо в ряду амидотионфосфатов.

Для синтеза макроциклов, содержащих по четыре остатка 2,7-дигидроксинафталина и фосфорсодержащих кислот, был использован принцип «оne pot» с трехкратным избытком диола 1: два моль участвуют в образовании соединения 35, а оставшийся моль в последующей циклизации. Через 4 ч от начала реакции в реакционную смесь вводили два моля амида $\mathbf{2 b}$ и оставляли на сутки.

Продукт циклизации 42 отделялся из раствора

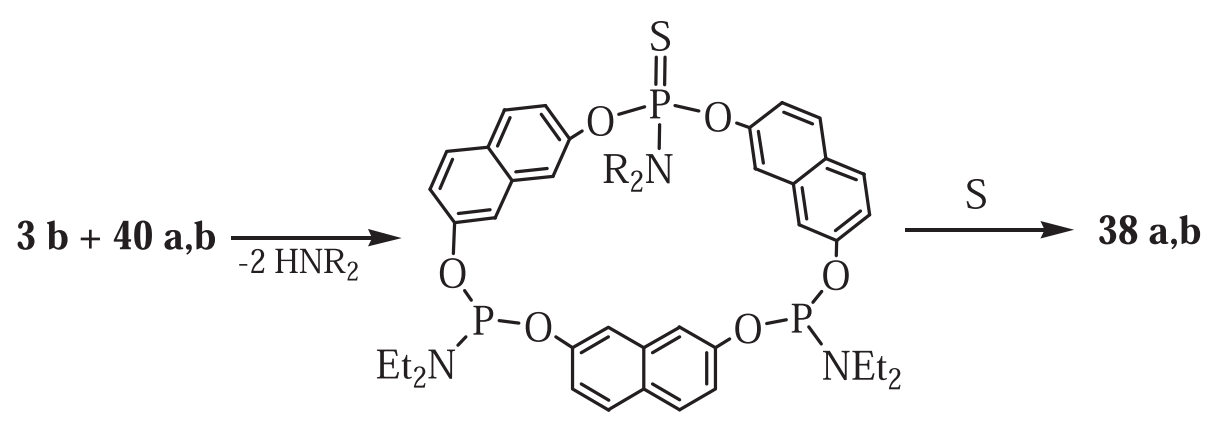

$41 \mathrm{a}, \mathrm{b}$ 


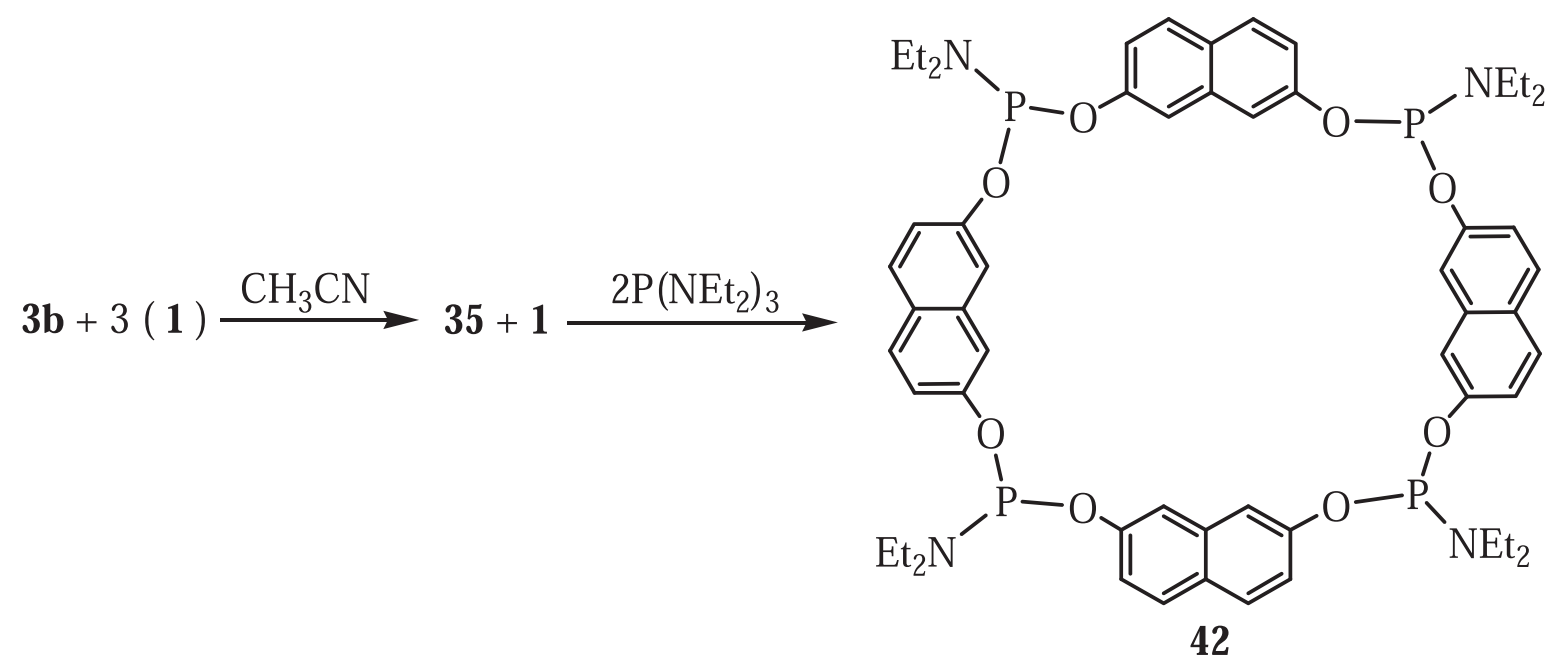

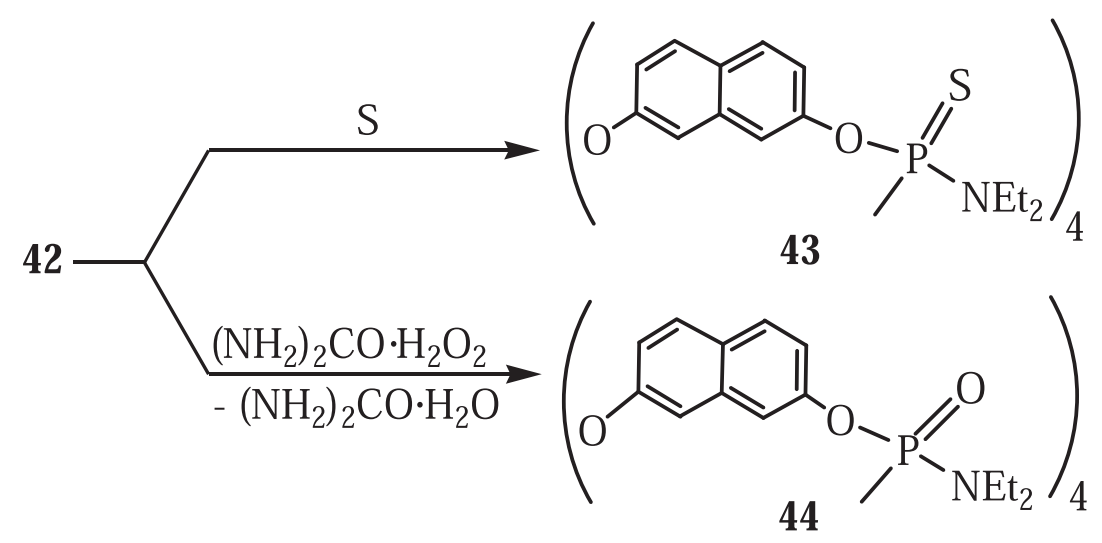

в виде масла, но после очистки представлял собой хрупкую пенку. В спектре ${ }^{31} \mathrm{P}$ ЯМР полученного соединения 42 наблюдался синглетный сигнал с $\delta 138.7$ м.д., характерный для моноамидофосфитов с арильными заместителями.

Кроме того, были осуществлены сульфуризация и окисление соединения 42.

Сульфуризация проходила легко при комнатной температуре в бензоле в течение суток. Полученный циклоамидотионфосфат 43 выделяли методом колоночной хроматографии. Продукт представлял собой порошкообразное бесцветное вещество с температурой плавления 224-226 ${ }^{\circ} \mathrm{C}$. В его спектрах ${ }^{31} \mathrm{P}$ ЯМР наблюдался сигнал с $\delta 67.3$ м.д., характерный для моноамидотионфосфатов. Спектр ${ }^{1} \mathrm{H}$ ЯМР соединения 43 был аналогичен спектру соединения 42, однако необходимо отметить, что сигнал метиленовых протонов смещался в более слабое поле, что характерно для соединений $\mathrm{P}^{\mathrm{V}}$.

Фосфат 44 был получен окислением циклофосфита 42 комплексом мочевины с пероксидом водорода в метиленхлориде при комнатной температуре в течение суток и выделен методом колоночной хроматографии. Он представлял собой порошкообразное вещество с температурой плавления $218-220^{\circ} \mathrm{C}$. Спектр ${ }^{1} \mathrm{H}$ ЯМР был аналогичен спектру соединения 45.

\section{Выводы}

1. Синтезирован ряд бис(диамидо)фосфитов, тионфосфатов и фосфатов 2,7-дигидроксинафталина.
2. Используя методы молекулярной сборки, прямого синтеза и дисмутации диамидофосфитов 2,7дигидроксинафталина, синтезированыкак«однородные», так и «неоднородные» макроциклических системы, содержащих два остатка фосфорных кислот и нафталина. Изучены их структурные особенности.

3. Используя метод молекулярной сборки олигосоединений на основе 2,7-дигидроксинафталина, содержащих амидофосфитные и тионамидофосфатные функции, синтезирован ряд макроциклических систем, содержащих по три и четыре остатка нафталина и фосфорных кислот и способных удерживать малые молекулы.

4. Строение и индивидуальность полученных соединений были доказаны методами ТСХ, ЯМР ${ }^{31} \mathrm{P},{ }^{1} \mathrm{H}$ и ${ }^{13} \mathrm{C}$, элементным анализом и определением молекулярной массы методом MALDI-TOF.

\section{Экспериментальная часть}

Спектры ${ }^{1} \mathrm{H}$ и ${ }^{13} \mathrm{C}$ ЯМР $\left(\mathrm{B}^{\mathrm{CDCl}_{3}}\right)$ регистрировали на прибope «Bruker AC-200» на частоте 200 и 80 МГц соответственно, спектры ${ }^{31} \mathrm{P}$ ЯMP на приборе «Bruker WP-80SY» на частоте 32.4 МГц. В качестве стандартов для спектров ЯМР ${ }^{1} \mathrm{H},{ }^{13} \mathrm{C}$ и ${ }^{31} \mathrm{P}$ применяли соответственно $\mathrm{Me}_{4} \mathrm{Si}$ (внутренний стандарт) и $85 \%$-ную $\mathrm{H}_{3} \mathrm{PO}_{4}$ (внешний эталон). Химические сдвиги даны в м.д., КССВ - в Гц.

Масс-спектры получены на приборе Reflex III фирмы «Bruker», растворитель - $\mathrm{CHCl}_{3}$, матрица - 2,4,6тригидроксиацетофенон. Все синтезы проводили с использованием безводных растворителей в атмосфере сухого азота.Адсорбционнуюхроматографиюнаколонкеосуществляли 
на силикагеле L 100/250 мкм, TCX - на пластинах Silufol в системах $\mathrm{C}_{6} \mathrm{H}_{6}$ - диоксан, 5:1 (А); гексан - диоксан, 5:1 (В); $\mathrm{C}_{6} \mathrm{H}_{6}$ - диоксан, 10:1 (C), $\mathrm{C}_{6} \mathrm{H}_{6}-\mathrm{EtOH}, 3: 1$ (D), $\mathrm{CHCl}_{3}$ - EtOH, $5: 1$ (Е). Обнаружение веществ осуществляли парами йода и прожиганием. Полные амиды фосфористой кислоты получены по следующим методикам: гексаметилтриамид фосфористой кислоты $\mathbf{2 a}]^{[37]}$ ГЭТА $\mathbf{2} \mathbf{b}$ и гексаизопропилтриамид фосфористой кислоты $\mathbf{2 c},{ }^{[38]}$ трипиперидид фосфористой кислоты $\mathbf{2 d} .^{[39]}$

2,7-Бис (тетраалкилдиамитотионфосфатокси)нафталины $(\mathbf{4 a - d})$. К 2,5 ммоль триамида фосфористой кислоты 2a-d при комнатной температуре и постоянном перемешивании добавляли 0,2 г (1,25 ммоль) 2,7-дигидроксинафталина (1) в 5 мл ацетонитрила. Через 5 мин (a), 15 мин (b), 1 ч (c) или 4 ч (d) в реакционную смесь вводили 0,08 г (2,5 ммоль) серы и перемешивали еще 3 часа. Затем раствор фильтровали, растворитель отгоняли в вакууме, а остаток хроматографировали на колонке, элюируя полученные продукты системой гексан-диоксан, 10:1. Полученные продукты сушили в вакууме 2 ч ( $\left.70{ }^{\circ} \mathrm{C}, 1 \mathrm{Topp}\right)$.

2,7-Бис (тетраметилдиамидотионфосфатокси)нафталин (4a). Выход 0,22 г (39\%). $\mathrm{T}_{\text {пл }} 154-155^{\circ} \mathrm{C} . \mathrm{R}_{f} 0.79$ (А). ${ }^{1} \mathrm{H}$ ЯМР

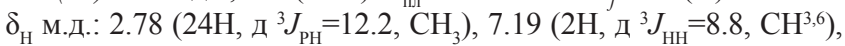
$7.45\left(2 \mathrm{H}, \mathrm{c}, \mathrm{CH}^{1,8}\right), 7.77\left(2 \mathrm{H}\right.$, д $\left.^{3} \mathrm{~J}_{\mathrm{HH}}=8.8, \mathrm{CH}^{4,5}\right) .{ }^{31} \mathrm{P}$ ЯMP $\left(\mathrm{CH}_{2} \mathrm{Cl}_{2}\right)$

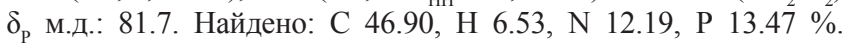
$\mathrm{C}_{18} \mathrm{H}_{30} \mathrm{~N}_{4} \mathrm{O}_{2} \mathrm{P}_{2} \mathrm{~S}_{2}$. Вычислено: С 46.93, Н 6.57, N 12.17, Р $13.46 \%$.

2,7-Бис (тетраэтилдиамидотионфосфатокси)нафталин (4b). Выход 0,3 г (42\%). $\mathrm{T}_{\text {п }} 104-105^{\circ} \mathrm{C} . \mathrm{R}_{f} 0.55(\mathrm{~B}), 0.62(\mathrm{C}) .{ }^{1} \mathrm{H}$ ЯМР $\delta_{\mathrm{H}}$ м.д.: $1.16\left(24 \mathrm{H}, \mathrm{T}^{\mathrm{n}}{ }^{3} J_{\mathrm{HH}}=7.0, \mathrm{CH}_{3}\right), 3.24\left(16 \mathrm{H}, \mathrm{M}^{3} J_{\mathrm{PH}}=12.8\right.$, $\left.\mathrm{CH}_{2}\right), 7.35\left(2 \mathrm{H}\right.$, д $\left.^{3} \mathrm{JH}_{\mathrm{Hн}}=8.8, \mathrm{CH}^{3,6}\right), 7.49\left(2 \mathrm{H}, \mathrm{c}, \mathrm{CH}^{1,8}\right), 7.74(2 \mathrm{H}$, д $\left.{ }^{3} J_{\mathrm{HH}}=8.8, \mathrm{CH}^{4,5}\right)$. ${ }^{31} \mathrm{P}$ ЯМР $\left(\mathrm{CH}_{2} \mathrm{Cl}_{2}\right) \delta_{\mathrm{p}}$ м.д.: 76.4. Найдено: С 54.32, Н 8.16, N 9.71, Р $10.85 \%$. С ${ }_{26} \mathrm{H}_{46} \mathrm{~N}_{4} \mathrm{O}_{2} \mathrm{P}_{2} \mathrm{~S}_{2}$ Вычислено: С 54.52, H 8.10, N 9.78, P $10.82 \%$.

2,7-Бис (тетраизопропилдиамидотионфосфатокси) нафталин (4c). Выход 0,4 г (47\%). $\mathrm{T}_{\text {пл }} 202-203{ }^{\circ} \mathrm{C} . \mathrm{R}_{f} 0.52$ (B), $0.63(\mathrm{C}) .{ }^{1} \mathrm{H}$ ЯМР $\delta_{\mathrm{H}}$ м.д.: $1.29\left(24 \mathrm{H}\right.$, д $\left.^{3} J_{\mathrm{HH}}=6.6, \mathrm{CH}_{3}\right), 1.41$ $\left(24 \mathrm{H}\right.$, д $\left.{ }^{3} \mathrm{H}_{\mathrm{HH}}=6.6, \mathrm{CH}_{3}\right), 3.84\left(4 \mathrm{H}\right.$, м $\left.^{3} J_{\mathrm{PH}}=13.2, \mathrm{CH}\right), 3.92(4 \mathrm{H}, \mathrm{м}$ $\left.{ }^{3} J_{\mathrm{PH}}=13.7, \mathrm{CH}\right), 7.51\left(2 \mathrm{H}\right.$, дд $\left.{ }^{3} J_{\mathrm{HH}}=9.4,{ }^{4} J_{\mathrm{HH}}=2.2, \mathrm{CH}^{3,6}\right), 7.72(2 \mathrm{H}$, д $\left.{ }^{3} J_{\text {нн }}=9.3, \mathrm{CH}^{4,5}\right), 7.85\left(2 \mathrm{H}, \mathrm{c}, \mathrm{CH}^{1,8}\right) .{ }^{31} \mathrm{P}$ ЯMР $\left(\mathrm{CH}_{2} \mathrm{Cl}_{2}\right) \delta_{\mathrm{P}}$ м.д.: 66.5. Найдено: С 59.58, Н 9.07, N 8.16, P 9.06\%. С ${ }_{34} \mathrm{H}_{62} \mathrm{~N}_{4} \mathrm{O}_{2} \mathrm{P}_{2} \mathrm{~S}_{2}$ Вычислено: С 59.62, Н 9.12, N 8.18, Р $9.04 \%$.

2,7-Бис (дипиперидиламидотионфосфатокси)нафталин (4d). Выход 0,34 г (44\%). Т $162-163{ }^{\circ} \mathrm{C} . \mathrm{R}_{f} 0.48(\mathrm{~B}) .{ }^{1} \mathrm{H}$ ЯMP $\delta_{\mathrm{H}}$ м.Д.: $1.60\left(24 \mathrm{H}, \mathrm{\text {м }}, \mathrm{CH}_{2}\right), 3.18\left(8 \mathrm{H}, \mathrm{M}^{3} \mathrm{~J}_{\mathrm{PH}}=7.2, \mathrm{C}^{\mathrm{a}} \mathrm{H}_{2}\right), 3.22(8 \mathrm{H}, \mathrm{M}$ $\left.{ }^{3} J_{\mathrm{PH}}=6.6, \mathrm{C}^{\mathrm{e}} \mathrm{H}_{2}\right), 7.25\left(2 \mathrm{H}\right.$, дд $\left.{ }^{3} J_{\mathrm{HН}}=8.3,{ }^{4} J_{\mathrm{HH}}=2.2, \mathrm{CH}^{3,6}\right), 7.51(2 \mathrm{H}$, c, $\left.\mathrm{CH}^{1,8}\right), 7.75\left(2 \mathrm{H}\right.$, д $\left.^{3} \mathrm{HH}_{\mathrm{HH}}=8.3, \mathrm{CH}^{4,5}\right) .{ }^{31} \mathrm{P}$ ЯMP $\left(\mathrm{CH}_{2} \mathrm{Cl}_{2}\right) \delta_{\text {р м.д.: }}$ 75.0. Найдено: С 58.06, Н 7.49, N 9.09, Р $9.94 \% . \mathrm{C}_{30} \mathrm{H}_{46} \mathrm{~N}_{4} \mathrm{O}_{2} \mathrm{P}_{2} \mathrm{~S}_{2}$ Вычислено: С 58.04, Н 7.47, N 9.03, Р 9.98 \%.

Цикло[бис(2,7-нафтиленалкиламидофосфиты)] (5a-d). Метод молекулярной сборки (общая методика). К 4 ммоль полного амида фосфористой кислоты 2a-d в 4 мл ацетонитрила при комнатной температуре и постоянном перемешивании добавляли 0,32 г (2 ммоль) нафтодиола 1 , растворенного в 2 мл ацетонитрила. Через 5 мин (a), 15 мин (b), 1 ч (c) или 4 ч (d) в реакционную смесь вводили еще 0,32 г (2 ммоль) нафтодиола 1 в 5 мл ацетонитрила и перемешивали 4 ч. Через сутки раствор над образовавшимся осадком декантировали, промывали полученный продукт ацетонитрилом и сушили в вакууме 3 ч $\left(70{ }^{\circ} \mathrm{C}, 1\right.$ Topp).

Метод прямого синтеза (общая методика). К 4 ммоль полного амида фосфористой кислоты 2a-d в 4 мл ацетонитрила при комнатной температуре и постоянном перемешивании добавляли 0,64 г (4 ммоль) нафтодиола 1 , растворенного в 5 мл ацетонитрила и перемешивали еще 4 ч. Через сутки раствор над образовавшимся осадком декантировали, промывали полученный продукт ацетонитрилом и сушили в вакууме 3 ч (70 ${ }^{\circ} \mathrm{C}, 1$ Topp).

Цикло[бис(2,7-нафтилендиметиламидофосфит)] (5a). Выход 0,63 г (68\%). Т тл $222-223{ }^{\circ} \mathrm{C} . \mathrm{R}_{f} 0.76(\mathrm{~A}) .{ }^{1} \mathrm{H}$ ЯМР $\delta_{\mathrm{H}}$ м.Д.: $2.83\left(12 \mathrm{H}\right.$, д $\left.^{3} J_{\mathrm{PH}}=9.4, \mathrm{CH}_{3}\right), 7.17\left(4 \mathrm{H}\right.$, д $\left.^{3} J_{\mathrm{HH}}=9.0, \mathrm{CH}^{3,6}\right), 7.35(4 \mathrm{H}, \mathrm{c}$, $\left.\mathrm{CH}^{1,8}\right), 7.71\left(4 \mathrm{H}\right.$, д $\left.^{3} \mathrm{HH}_{\mathrm{HH}}=9.0, \mathrm{CH}^{4,5}\right) .{ }^{31} \mathrm{P}$ ЯМР $\left(\mathrm{CH}_{2} \mathrm{Cl}_{2}\right) \delta_{\mathrm{P}}$ м.д.: 139.8 . Найдено: С 61.45, Н 5.31, Р $12.91 \% . \mathrm{C}_{24} \mathrm{H}_{24} \mathrm{~N}_{2} \mathrm{O}_{4} \mathrm{P}_{2} . \mathrm{m} / z$ (MALDI) 466.21. Вычислено: С 61.79, Н 5.18, Р $13.08 \%$ \%. M 466.41.

Цикло[бис(2,7-нафтилендиэтиламидофосфит)] (5b). Выход 0,66 г (63\%). $\mathrm{T}_{\text {тा }} 114-115{ }^{\circ} \mathrm{C} . \mathrm{R}_{f} 0.84$ (A), 0.76 (C). ${ }^{1} \mathrm{H}$ ЯМР $\delta_{\mathrm{H}}$ м.д.: $1.07\left(12 \mathrm{H}, \mathrm{T}{ }^{3} J_{\mathrm{HH}}=7.3, \mathrm{CH}_{3}\right), 3.28\left(8 \mathrm{H}, \mathrm{M}^{3} J_{\mathrm{PH}}=10.3\right.$, $\left.\mathrm{CH}_{2}\right), 7.17\left(4 \mathrm{H}\right.$, дд $\left.{ }^{3} J_{\mathrm{HH}}=8.5,{ }^{4} J_{\mathrm{HH}}=2.1, \mathrm{CH}^{3,6}\right), 7.34\left(4 \mathrm{H}, \mathrm{c}, \mathrm{CH}^{1,8}\right)$, $7.86\left(4 \mathrm{H}\right.$, д $\left.{ }^{3} J_{\mathrm{HН}}=8.5, \mathrm{CH}^{4,5}\right) .{ }^{31} \mathrm{P}$ ЯМР $\left(\mathrm{CH}_{2} \mathrm{Cl}_{2}\right) \delta_{\mathrm{P}}$ м.д.: 140.5. Найдено: Р 11.51 \%. $\mathrm{C}_{28} \mathrm{H}_{32} \mathrm{~N}_{2} \mathrm{O}_{4} \mathrm{P}_{2}$ Вычислено: Р $11.86 \%$.

Цикло[бис(нафтилендиэтиламидофосфиты)] (1621) (общая методика). К 4 ммоль ГЭТА 2b при комнатной температуре и перемешивании добавляли 2 ммоль ароматического диола (1, 7a-d, 8) в 15 мл ацетонирила. Через определенный промежуток времени (см. табл. 1) к реакционной смеси добавляли 2 ммоль другого ароматического диола в 10 мл ацетонитрила. Смесь перемешивали 4 ч и оставляли на 48 ч. Затем раствор над выпавшим осадком декантировали, циклофосфит промывали ацетонитрилом и сушили в вакууме 2 ч $\left(70^{\circ} \mathrm{C}, 1\right.$ Topp $)$.

Цикло[(1,7-нафтилен)-(2,7-нафтилен)-бис(диэтиламидофосфит)] (14). Выход 0,74 г (71\%). Маслообразное вещество. $\mathrm{R}_{f} 0.76$ (А). ${ }^{1} \mathrm{H}$ ЯМР $\delta_{\mathrm{H}}$ м.д.: $1.02\left(12 \mathrm{H}\right.$, уш.т ${ }^{3} J_{\mathrm{HН}}=5.9$, $\left.\mathrm{CH}_{3}\right), 3.25-3.41$ (8H, уш.м, $\left.\mathrm{CH}_{2}\right), 7.40-8.10$ (12H, уш.м, $\left.\mathrm{CH}\right)$.

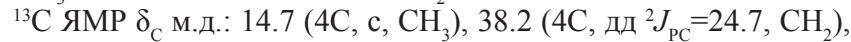
$110.3\left(1 \mathrm{C}\right.$, д $\left.{ }^{3} J_{\mathrm{PC}}=6.0, \mathrm{C}^{2} \mathrm{H}\right), 113.4\left(1 \mathrm{C}\right.$, д $\left.{ }^{3} J_{\mathrm{PC}}=5.8, \mathrm{C}^{8} \mathrm{H}\right), 114.5$

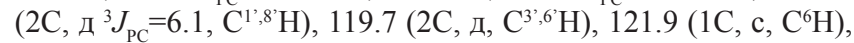
$122.3\left(1 \mathrm{C}, \mathrm{c}, \mathrm{C}^{4} \mathrm{H}\right), 124.1\left(1 \mathrm{C}, \mathrm{c}, \mathrm{C}^{5} \mathrm{H}\right), 126.4\left(1 \mathrm{C}, \mathrm{c}, \mathrm{C}^{3} \mathrm{H}\right), 128.4$ $\left(1 \mathrm{C}, \mathrm{c}, \mathrm{C}^{4,5} \mathrm{H}\right), 129.1\left(1 \mathrm{C}, \mathrm{c}, \mathrm{C}^{9}\right), 131.3\left(1 \mathrm{C}, \mathrm{c}, \mathrm{C}^{10^{\prime}}\right), 135.4(1 \mathrm{C}, \mathrm{c}$, $\left.\mathrm{C}^{9}, 10\right), 149.3\left(1 \mathrm{C}\right.$, д $\left.^{2} J_{\mathrm{PC}}=11.8, \mathrm{C}^{1} \mathrm{O}\right), 151.6\left(1 \mathrm{C}\right.$, д $\left.^{2} J_{\mathrm{PC}}=12.1, \mathrm{C}^{7} \mathrm{O}\right)$, $152.2\left(2 \mathrm{C}\right.$, д $\left.^{2} J_{\mathrm{PC}}=12.0, \mathrm{C}^{2}, 7 \mathrm{O}\right) .{ }^{31} \mathrm{P}$ ЯМР $\left(\mathrm{CH}_{2} \mathrm{Cl}_{2}\right) \delta_{\mathrm{p}}$ м.д.: 140.8 . Найдено: Р 11.59 \%. $\mathrm{C}_{28} \mathrm{H}_{32} \mathrm{~N}_{2} \mathrm{O}_{4} \mathrm{P}_{2}$. Вычислено: Р $11.86 \%$.

Цикло [( 1,6-нафтилен) - (2, 7 - нафтилен) бис(диэтиламидофосфит) (15). Выход 0,82 г (78\%). Т п 111-113 ${ }^{\circ} \mathrm{C} . \mathrm{R}_{f} 0.61$ (A). ${ }^{1} \mathrm{H}$ ЯМР $\delta_{\mathrm{H}}$ м.д.: $1.09\left(12 \mathrm{H}, \mathrm{T}^{3} \mathrm{~J}_{\mathrm{HH}}=8.1, \mathrm{CH}_{3}\right), 3.32$ $\left(8 \mathrm{H}, \mathrm{M}^{3} J_{\mathrm{PH}}=12.2, \mathrm{CH}_{2}\right), 7.06\left(1 \mathrm{H}\right.$, д $\left.{ }^{3} J_{\mathrm{Hн}}=7.3, \mathrm{CH}^{2}\right), 7.17(2 \mathrm{H}$, д $\left.{ }^{3} J_{\mathrm{HH}}=8.8, \mathrm{CH}^{3}, 6^{6}\right), 7.23\left(1 \mathrm{H}\right.$, д $\left.^{3} J_{\mathrm{HH}}=8.5, \mathrm{CH}^{7}\right), 7.31\left(1 \mathrm{H},{ }^{3} J_{\mathrm{HH}}=7.3\right.$, $\left.\mathrm{CH}^{3}\right), 7.36\left(1 \mathrm{H}, \mathrm{c}, \mathrm{CH}^{5}\right), 7.41\left(2 \mathrm{H}, \mathrm{c}, \mathrm{CH}^{1}, 8^{2}\right), 7.43\left(1 \mathrm{H}\right.$, д $^{3} J_{\mathrm{нH}}=7.7$, $\left.\mathrm{CH}^{4}\right), 7.70\left(2 \mathrm{H}\right.$, д $\left.^{3} J_{\mathrm{HH}}=8.8, \mathrm{CH}^{4}, 5^{\prime}\right), 8.15\left(1 \mathrm{H}\right.$, д $\left.^{3} J_{\mathrm{HH}}=8.5, \mathrm{CH}^{8}\right) .{ }^{31} \mathrm{P}$ ЯМР $\left(\mathrm{CH}_{2} \mathrm{Cl}_{2}\right) \delta_{\mathrm{p}}$ м.д.: 140.9. Найдено: С 64.13, Н 6.22, N 5.40, Р $11.48 \%$. $\mathrm{C}_{28} \mathrm{H}_{32} \mathrm{~N}_{2} \mathrm{O}_{4} \mathrm{P}_{2} . m / z$ (MALDI) 522.6. Вычислено: С 64.36, H 6.18, N 5.36, P $11.86 \%$. M 522.2.

Цикло[(1,5-нафтилен)-(2,7-нафтилен)-бис(диэтиламидофосфит)] (16). Выход 0,76 г (73\%). Маслообразное вещество. $\mathrm{R}_{f} 0.77$ (А). ${ }^{1} \mathrm{H}$ ЯМР $\delta_{\mathrm{H}}$ м.д.: $1.10\left(12 \mathrm{H},{ }^{3}{ }^{3} J_{\mathrm{HH}}=7.5\right.$, $\left.\mathrm{CH}_{3}\right), 3.34\left(8 \mathrm{H}, \mathrm{M}^{3} J_{\mathrm{PH}}=10.3, \mathrm{CH}_{2}\right), 7.15\left(2 \mathrm{H}\right.$, д, $\left.{ }^{3} J_{\mathrm{Hн}}=8.8, \mathrm{CH}^{3}, 6^{\prime}\right)$, $7.18\left(2 \mathrm{H}\right.$, д, $\left.\mathrm{CH}^{2,6}\right), 7.34\left(2 \mathrm{H}, \mathrm{T}^{3} J_{\mathrm{HH}}=8.3, \mathrm{CH}^{3,7}\right), 7.36(2 \mathrm{H}, \mathrm{c}$, $\left.\mathrm{CH}^{1,8^{\prime}}\right), 7.69\left(2 \mathrm{H}\right.$, д $\left.^{3} J_{\mathrm{Hн}}=8.8, \mathrm{CH}^{4}, 5^{\prime}\right), 7.90\left(2 \mathrm{H}\right.$, д $\left.^{3} J_{\mathrm{HH}}=8.3, \mathrm{CH}^{4,8}\right)$. ${ }^{31} \mathrm{P}$ ЯМР $\left(\mathrm{CH}_{2} \mathrm{Cl}_{2}\right) \delta_{\mathrm{p}}$ м.д.: 140.9. Найдено: С 64.10, Н 6.22, N 5.48, Р $11.55 \%$. $\mathrm{C}_{28} \mathrm{H}_{32} \mathrm{~N}_{2} \mathrm{O}_{4} \mathrm{P}_{2}$. Вычислено: С 64.36, Н 6.18, N 5.36, P $11.86 \%$.

Цикло[(2, 6-нафтилен)-(2,7-нафтилен)-бис(диэтиламидофосфит)] (17). Выход 0,82 г (78\%). $\mathrm{T}_{\text {пл }} 112-114{ }^{\circ} \mathrm{C} . \mathrm{R}$ 0.59 (А). ${ }^{1} \mathrm{H}$ ЯМР $\delta_{\text {Н }}$ м.д.: $1.08\left(12 \mathrm{H}, \mathrm{T}^{3} \mathrm{~J}_{\mathrm{HH}}=7.0, \mathrm{CH}_{3}\right), 3.29(8 \mathrm{H}$, м $\left.{ }^{3} J_{\mathrm{PH}}=10.5, \mathrm{CH}_{2}\right), 7.16\left(2 \mathrm{H}\right.$, д $\left.{ }^{3} J_{\mathrm{HH}}=8.9, \mathrm{CH}^{3^{3}, 6^{\prime}}\right), 7.25(2 \mathrm{H}$, д $\left.{ }^{3} J_{\mathrm{HH}}=9.2, \mathrm{CH}^{3,7}\right), 7.36\left(2 \mathrm{H}, \mathrm{c}, \mathrm{CH}^{1,8}\right), 7.42\left(2 \mathrm{H}, \mathrm{c}, \mathrm{CH}^{1,5}\right), 7.65(2 \mathrm{H}$, д $\left.^{3} J_{\mathrm{Hн}}=9.2, \mathrm{CH}^{4,8}\right), 7.70\left(2 \mathrm{H}\right.$, д $\left.^{3} J_{\mathrm{Hн}}=8.9, \mathrm{CH}^{4}, 5^{\prime}\right) .{ }^{31} \mathrm{P}$ ЯМР $\left(\mathrm{CH}_{2} \mathrm{Cl}_{2}\right)$

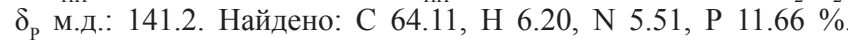
$\mathrm{C}_{28} \mathrm{H}_{32} \mathrm{~N}_{2} \mathrm{O}_{4} \mathrm{P}_{2}$. Вычислено: С 64.36, Н 6.18, N 5.36, Р $11.86 \%$.

1,9-Бис(диэтиламидо)-15,15-диметил-3,4,5, 6, 7-нафто11,12,13,14;16,17,18,19-дибензо-2,8,10,20-тетраокси-1,9дифосфоииклоэйкозан (18). Выход 0,33 г (54\%). T ${ }^{\circ} \mathrm{C} .{ }^{1} \mathrm{H}$ ЯМР $\delta_{\mathrm{H}}$ м.д.: $1.16\left(12 \mathrm{H}, \mathrm{T}^{3} J_{\mathrm{HН}}=7.5, \mathrm{CH}_{3}\right), 1.63(6 \mathrm{H}, \mathrm{c}$, $\left.\mathrm{C}\left(\mathrm{CH}_{3}\right)_{2}\right), 3.33\left(8 \mathrm{H}\right.$, м $\left.{ }^{3} J_{\mathrm{PH}}=11.9, \mathrm{CH}_{2}\right), 6.97\left(4 \mathrm{H}\right.$, д ${ }^{3} J_{\mathrm{HH}}=8.2$, $\left.\mathrm{CH}^{2,6}\right), 7.14\left(4 \mathrm{H}\right.$, д $\left.\left.^{3} J_{\mathrm{HH}}=8.9, \mathrm{CH}^{3,5}\right), 7.18\left(2 \mathrm{H}, \mathrm{c}, \mathrm{CH}^{1,8}\right)^{\prime}\right), 7.27(2 \mathrm{H}$, д $\left.^{3} J_{\mathrm{HH}}=8.3, \mathrm{CH}^{3^{\prime}, 6^{\prime}}\right), 7.87\left(2 \mathrm{H}\right.$, д $\left.^{3} J_{\mathrm{Hн}}=8.3, \mathrm{CH}^{4}, 5^{\prime}\right) .{ }^{31} \mathrm{P}$ ЯMP $\left(\mathrm{CH}_{2} \mathrm{Cl}_{2}\right)$

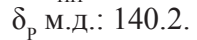


1,9-Бис(диэтиламидо)-13,13-дигидро-3,4,5, 6, 7-нафто11,12;14,15-ди(1,2-нафто)-2,8,10,16-тетраокси-1,9-дифосфоциклодекагексан (19). Выход 0,36 (52\%). Маслообразное вещество. $\mathrm{R}_{f} 0.77(\mathrm{~A}) .{ }^{1} \mathrm{H}$ ЯМР $\delta_{\mathrm{H}}$ м.д.: $1.25\left(12 \mathrm{H},{ }^{3} J_{\mathrm{HH}}=6.9\right.$, $\left.\mathrm{CH}_{3}\right), 3.31\left(8 \mathrm{H}, \mathrm{M}^{3} J_{\mathrm{PH}}=11.0, \mathrm{CH}_{2}\right), 4.55\left(1 \mathrm{H}\right.$, д $\left.^{2} J_{\mathrm{HН}}=16.1, \mathrm{CH}_{2 \text { (мост })}\right)$, $5.25\left(1 \mathrm{H}\right.$, д $\left.^{2} J_{\mathrm{Hн}}=16.1, \mathrm{CH}_{2 \text { (мост) }}\right), 7.17\left(2 \mathrm{H}\right.$, д, $\left.\mathrm{CH}^{1,7}\right), 7.22(2 \mathrm{H}$, д $\left.{ }^{3} J_{\mathrm{HH}}=9.1, \mathrm{CH}^{3,3}, 3^{\prime \prime}\right), 7.41\left(2 \mathrm{H}\right.$, м $\left.{ }^{3} J_{\mathrm{HH}}=6.2 ; 6.9, \mathrm{CH}^{3,6}\right), 7.45(2 \mathrm{H}$, c, $\left.\mathrm{CH}^{6,6 "}\right), 7.52\left(2 \mathrm{H}, \mathrm{m}^{3} J_{\mathrm{Hн}}=6.9,{ }^{4} J_{\mathrm{Hн}}=1.5, \mathrm{CH}^{7}, 77^{\prime \prime}\right), 7.64(2 \mathrm{H}$, д, $\left.\mathrm{CH}^{4,4} 4^{\prime \prime}\right), 7.79\left(2 \mathrm{H}\right.$, д $\left.^{3} \mathrm{HH}_{\mathrm{HH}}=8.4, \mathrm{CH}^{4,5}\right), 7.88\left(2 \mathrm{H}\right.$, д $\left.^{3} \mathrm{HH}_{\mathrm{HH}}=8.0, \mathrm{CH}^{5,5^{\prime \prime}}\right)$, $8.36\left(2 \mathrm{H}\right.$, дд $\left.{ }^{3} J_{\mathrm{HH}}=8.4,{ }^{4} J_{\mathrm{HH}}=1.5, \mathrm{CH}^{8,}, 8^{\prime \prime}\right) .{ }^{31} \mathrm{P}$ ЯМР (1,4-диоксан) $\delta_{\mathrm{P}}$ м.д.: 141.3

Сульфуризаиия (общая методика). К раствору 1 ммоль циклофосфита (5a-d, 14-19) в 4 мл сухого метиленхлорида при комнатной температуре и постоянном перемешивании добавляли 0,064 г (2 ммоль) серы. Через сутки растворитель отгоняли в вакууме, а остаток хроматографировали на колонке, элюируя продукты системой бензол-диоксан, 10:1. Полученные продукты сушили в вакууме 2 ч $\left(70^{\circ} \mathrm{C}, 1 \mathrm{Topp}\right)$.

Цикло[бис(2,7-нафтилендиметиламидотионфосфат)] (21a). Выход 0,25 г (47\%). $\mathrm{T}_{\text {пи }} 208-210{ }^{\circ} \mathrm{C} . \mathrm{R}_{f} 0.82$ (A). ${ }^{1} \mathrm{H}$ ЯMP $\delta_{\mathrm{H}}$ м.д.: $3.02\left(12 \mathrm{H}\right.$, д $\left.^{3} J_{\text {РН }}=11.9, \mathrm{CH}_{3}\right), 7.34\left(4 \mathrm{H}\right.$, д $\left.^{3} J_{\mathrm{HH}}=9.3, \mathrm{CH}^{3,6}\right), 7.62$ $\left(4 \mathrm{H}, \mathrm{c}, \mathrm{CH}^{1,8}\right), 7.80\left(4 \mathrm{H}\right.$, д $\left.^{3} J_{\mathrm{Hн}}=9.3, \mathrm{CH}^{4,5}\right) .{ }^{31} \mathrm{P}$ ЯМР $\left(\mathrm{CH}_{2} \mathrm{Cl}_{2}\right) \delta_{\mathrm{p}}$ м.д.: 68.3. Найдено: Р $11.58 \%$. С ${ }_{24} \mathrm{H}_{24} \mathrm{~N}_{2} \mathrm{O}_{4} \mathrm{P}_{2} \mathrm{~S}_{2}$. Вычислено: Р $11.67 \%$.

Цикло[бис(2, 7-нафтилендиэтиламидотионфосфат)] (21b). Выход 0,26 г (49\%). T $158-159^{\circ} \mathrm{C} . \mathrm{R}_{f} 0.79$ (A). ${ }^{1} \mathrm{H}$ ЯМР $\delta_{\mathrm{H}}$ м.д.: $1.18\left(12 \mathrm{H}, \mathrm{T}^{3} \mathrm{~J}_{\mathrm{HH}}=6.8, \mathrm{CH}_{3}\right), 3.50\left(8 \mathrm{H}_{,} \mathrm{M}^{3} \mathrm{~J}_{\mathrm{PH}}=13.9, \mathrm{CH}_{2}\right), 7.35$ $\left(4 \mathrm{H}\right.$, д $\left.{ }^{3} J_{\mathrm{Hн}}=8.8, \mathrm{CH}^{3,6}\right), 7.63\left(4 \mathrm{H}\right.$, с, $\left.\mathrm{CH}^{1,8}\right), 7.79\left(4 \mathrm{H}\right.$, д $^{3} J_{\mathrm{HH}}=8.8$, $\left.\mathrm{CH}^{4,5}\right) .{ }^{31} \mathrm{P}$ ЯМР $\left(\mathrm{CH}_{2} \mathrm{Cl}_{2}\right) \delta_{\mathrm{p}}$ м.д.: 67.3. Найдено: С 57.29, Н 5.48, $\mathrm{N}$ 4.75, P $10.57 \%$. $m / z$ (MALDI) 588.4. $\mathrm{C}_{28} \mathrm{H}_{32} \mathrm{~N}_{2} \mathrm{O}_{4} \mathrm{P}_{2} \mathrm{~S}_{2}$. Вычислено C 57.32, H 5.50, N 4.77, P $10.56 \%$. M 586.64.

Цикло[бис(2,7-нафтилендиизопропиламидотионфосфam)] (21c). Выход 0,23 г (36\%). $\mathrm{T}_{\text {т }} 53-55{ }^{\circ} \mathrm{C} . \mathrm{R}_{f} 0.71(\mathrm{C}) .{ }^{1} \mathrm{H}$

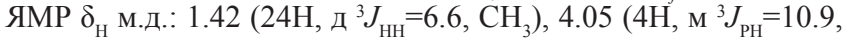
$\mathrm{CH}), 7.48\left(4 \mathrm{H}\right.$, д $\left.^{3} J_{\mathrm{нH}}=8.8, \mathrm{CH}^{3,6}\right), 7.63\left(4 \mathrm{H}, \mathrm{c}, \mathrm{CH}^{1,8}\right), 7.76(4 \mathrm{H}$, д $\left.{ }^{3} J_{\mathrm{Hн}}=8.8, \mathrm{CH}^{4,5}\right) .{ }^{31} \mathrm{P}$ ЯМР $\left(\mathrm{CH}_{2} \mathrm{Cl}_{2}\right) \delta_{\mathrm{p}}$ м.д.: 61.7. Найдено: С 59.89, Н 6.31, N 4.41, Р $9.57 \% \mathrm{C}_{32} \mathrm{H}_{40} \mathrm{~N}_{2} \mathrm{O}_{4} \mathrm{P}_{2} \mathrm{~S}_{2}$. Вычислено: С 59.80, H 6.27, N 4.36, P $9.64 \%$.

Цикло[(1,7-нафтилен)-(2,7-нафтилен)-бис(диэтиламидотионфосфат)] (22). Выход 0,29 г (52\%). Маслообразное вещество. $\mathrm{R}_{f} 0.78$ (А). ${ }^{1} \mathrm{H}$ ЯМР $\delta_{\mathrm{H}}$ м.д.: $1.10\left(12 \mathrm{H}\right.$, уш.т ${ }^{3} J_{\mathrm{Hн}}=8.0$, $\left.\mathrm{CH}_{3}\right), 3.39-3.52\left(8 \mathrm{H}\right.$, уш.м, $\left.\mathrm{CH}_{2}\right), 7.37-8.06(12 \mathrm{H}$, уш.м, $\mathrm{CH})$.

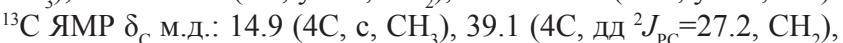
$110.9\left(1 \mathrm{C}\right.$, д $\left.{ }^{3} J_{\mathrm{PC}}=4.9, \mathrm{C}^{2} \mathrm{H}\right), 113.4\left(1 \mathrm{C}\right.$, д $\left.{ }^{3} J_{\mathrm{PC}}=5.5, \mathrm{C}^{8} \mathrm{H}\right), 115.1$ $\left(2 \mathrm{C}\right.$, д $\left.{ }^{3} J_{\mathrm{PC}}=11.0, \mathrm{C}^{1}, 8^{\prime} \mathrm{H}\right), 120.4\left(2 \mathrm{C}\right.$, д $\left.{ }^{3} J_{\mathrm{PC}}=5.8, \mathrm{C}^{3,}, 6^{\prime} \mathrm{H}\right), 121.0$ (1C, c, $\left.\mathrm{C}^{6} \mathrm{H}\right), 122.6\left(1 \mathrm{C}, \mathrm{c}, \mathrm{C}^{4} \mathrm{H}\right), 125.2\left(1 \mathrm{C}, \mathrm{c}, \mathrm{C}^{5} \mathrm{H}\right), 127.0$ (1C, c, $\left.\mathrm{C}^{3} \mathrm{H}\right), 129.2\left(1 \mathrm{C}, \mathrm{c}, \mathrm{C}^{4^{\prime}, 5^{\prime}} \mathrm{H}\right), 129.4\left(1 \mathrm{C}, \mathrm{c}, \mathrm{C}^{9}\right), 131.9\left(1 \mathrm{C}, \mathrm{c}, \mathrm{C}^{10^{9}}\right)$, $134.9\left(1 \mathrm{C}, \mathrm{c}, \mathrm{C}^{9}, 10\right), 150.1\left(1 \mathrm{C}\right.$, д $\left.^{2} J_{\mathrm{PC}}=11.2, \mathrm{C}^{1} \mathrm{O}\right), 151.7(1 \mathrm{C}$, д $\left.{ }^{2} J_{\mathrm{PC}}=11.0, \mathrm{C}^{7} \mathrm{O}\right), 152.8\left(2 \mathrm{C}, \mathrm{д}^{2} J_{\mathrm{PC}}=10.9, \mathrm{C}^{2,7} \mathrm{O} \mathrm{O}\right) .{ }^{31} \mathrm{P}$ ЯMP $\left(\mathrm{CH}_{2} \mathrm{Cl}_{2}\right)$ $\delta_{\mathrm{p}}$ м.д.: 66.9. Найдено: Р $10.59 \%$. $\mathrm{C}_{28} \mathrm{H}_{32} \mathrm{~N}_{2} \mathrm{O}_{4} \mathrm{P}_{2} \mathrm{~S}_{2}$ Вычислено: P $10.56 \%$

Цикло[(1,6-нафтилен)-(2,7-нафтилен)-бис(диэтиламидотионфосфат) (23). Выход 0,28 г (51\%). T $106-108{ }^{\circ} \mathrm{C}$. $\mathrm{R}_{f} 0.80(\mathrm{~A}) .{ }^{1} \mathrm{H}$ ЯМР $\delta_{\mathrm{H}}$ м.д.: $1.16\left(12 \mathrm{H}, \mathrm{T}^{3} J_{\mathrm{HH}}=7.2, \mathrm{CH}_{3}\right), 3.49(8 \mathrm{H}$, $\left.\mathrm{M}^{3} J_{\mathrm{PH}}=13,8, \mathrm{CH}_{2}\right), 7.36\left(1 \mathrm{H}\right.$, д $\left.^{3} J_{\mathrm{HH}}=7.7, \mathrm{CH}^{2}\right), 7.41\left(1 \mathrm{H}\right.$, д $^{3} J_{\mathrm{HH}}=9.4$, $\left.\mathrm{CH}^{7}\right), 7.53\left(2 \mathrm{H}\right.$, д $\left.^{3} J_{\mathrm{HH}}=8.8, \mathrm{CH}^{3}, 6^{3}\right), 7.55\left(1 \mathrm{H},{ }^{3} J_{\mathrm{HH}}=7.7, \mathrm{CH}^{3}\right)$, $7.60\left(1 \mathrm{H}\right.$, д $\left.^{3} \mathrm{JH}_{\mathrm{HH}}=7.8, \mathrm{CH}^{4}\right), 7.62\left(1 \mathrm{H}, \mathrm{c}, \mathrm{CH}^{5}\right), 7.43\left(2 \mathrm{H}, \mathrm{c}, \mathrm{CH}^{1,8} 8^{\prime}\right)$, $7.77\left(2 \mathrm{H}\right.$, д $\left.^{3} J_{\mathrm{Hн}}=8.8, \mathrm{CH}^{4}, 5^{\prime}\right), 8.04\left(1 \mathrm{H}\right.$, д $\left.^{3} \mathrm{HH}_{\mathrm{HH}}=9.4, \mathrm{CH}^{8}\right) .{ }^{31} \mathrm{P}$ ЯМР $\left(\mathrm{CH}_{2} \mathrm{Cl}_{2}\right) \delta_{\text {р }}$ м.д.: 67.1. Найдено: Р $10.59 \%$. $\mathrm{C}_{28} \mathrm{H}_{32} \mathrm{~N}_{2} \mathrm{O}_{4} \mathrm{P}_{2} \mathrm{~S}_{2}$. Вычислено: Р $10.56 \%$

Цикло[(1,5-нафтилен)-(2,7-нафтилен)-бис(диэтиламидотионфосфат)] (24). Выход 0,28 г (51\%). Маслообразное вещество. $\mathrm{R}_{f} 0.77$ (А). ${ }^{1} \mathrm{H}$ ЯМР $\delta_{\mathrm{H}}$ м.Д.: $1.19\left(12 \mathrm{H},{ }^{3}{ }^{3} J_{\mathrm{HH}}=6.8\right.$, $\left.\mathrm{CH}_{3}\right), 3.71\left(8 \mathrm{H}, \mathrm{m}^{3} \mathrm{~J}_{\mathrm{PH}}=12.1, \mathrm{CH}_{2}\right), 7.32\left(2 \mathrm{H}, \mathrm{c}, \mathrm{CH}^{1}, 8^{\prime}\right), 7.38(2 \mathrm{H}$, д, $\left.{ }^{3} J_{\mathrm{HH}}=8.7, \mathrm{CH}^{3}, 6^{6}\right), 7.58\left(2 \mathrm{H}\right.$, д $\left.^{3} J_{\mathrm{HH}}=7.1, \mathrm{CH}^{2,6}\right), 7.64\left(2 \mathrm{H}, \mathrm{T}^{3} J_{\mathrm{HH}}=8.3\right.$, $\left.\mathrm{CH}^{3,7}\right), 7.70\left(2 \mathrm{H}\right.$, д $\left.^{3} J_{\mathrm{Hн}}=8.6, \mathrm{CH}^{4^{4}, 5^{5}}\right), 7.83\left(2 \mathrm{H}\right.$, д $\left.^{3} J_{\mathrm{HH}}=8.3, \mathrm{CH}^{4,8}\right) .{ }^{31} \mathrm{P}$ ЯMP $\left(\mathrm{CH}_{2} \mathrm{Cl}_{2}\right) \delta_{\mathrm{p}}$ м.д.: 66.8. Найдено: Р $10.58 \%$. $\mathrm{C}_{28} \mathrm{H}_{32} \mathrm{~N}_{2} \mathrm{O}_{4} \mathrm{P}_{2} \mathrm{~S}_{2}$. Вычислено: Р $10.56 \%$
Цикло[(2,6-нафтилен)-(2,7-нафтилен)-бис(диэтиламидотионфосфат)] (25). Выход 0,29 г (52\%). $\mathrm{T} 121-123{ }^{\circ} \mathrm{C}$. $\mathrm{R}_{f} 0.68$ (A), 0.64 (D). ${ }^{1} \mathrm{H}$ ЯМР $\delta_{\mathrm{H}}$ м.Д.: $1.03\left(12 \mathrm{H}, \mathrm{T}^{3} J_{\mathrm{HH}}=6.9, \mathrm{CH}_{3}\right)$, $3.41\left(8 \mathrm{H}\right.$, м $\left.^{3} J_{\mathrm{PH}}=12.5, \mathrm{CH}_{2}\right), 7.28\left(2 \mathrm{H}\right.$, д $\left.^{3} J_{\mathrm{HН}}=8.8, \mathrm{CH}^{3}, 6^{6}\right), 7.36$ $\left(2 \mathrm{H}\right.$, д $\left.\left.^{3} \mathrm{Hн}_{\mathrm{Hн}}=8.8, \mathrm{CH}^{3,7}\right), 7.54\left(2 \mathrm{H}, \mathrm{c}, \mathrm{CH}^{1,5}\right), 7.66\left(2 \mathrm{H}, \mathrm{c}, \mathrm{CH}^{1,8}\right)^{\prime}\right)$, $7.74\left(2 \mathrm{H}\right.$, д $\left.^{3} \mathrm{JH}_{\mathrm{HH}}=8.8, \mathrm{CH}^{4,8}\right), 7.96\left(2 \mathrm{H}\right.$, д $\left.^{3} \mathrm{~J}_{\mathrm{HH}}=8.7, \mathrm{CH}^{4,5}\right) .{ }^{31} \mathrm{P}$ ЯMP $\left(\mathrm{CH}_{2} \mathrm{Cl}_{2}\right) \delta_{\mathrm{p}}$ м.д.: 66.5. Найдено: Р $10.54 \%$. m/z (MALDI) 586.32. $\mathrm{C}_{28} \mathrm{H}_{32} \mathrm{~N}_{2} \mathrm{O}_{4} \mathrm{P}_{2}$. Вычислено: Р $10.56 \%$. M 586.12 .

1,9-Бис (диэтиламидо)-1,9-дитион-15,15-диметил3,4,5, 6, 7-нафто-11,12,13,14;16,17,18,19-дибензо-2,8,10,20тетраокси-1,9-дифосфочиклоэйкозан (26). Выход 0,43 г (66\%). $\mathrm{T}_{\mathrm{rн}} 87-88^{\circ} \mathrm{C} . \mathrm{R}_{f} 0.80(\mathrm{~A}) .{ }^{1} \mathrm{H}$ ЯМР $\delta_{\mathrm{H}}$ м.д.: $1.16\left(12 \mathrm{H}, \mathrm{T}^{3} \mathrm{~J}_{\mathrm{HН}}=7.2\right.$, $\left.\mathrm{CH}_{3}\right), 1.65,1.67\left(6 \mathrm{H}, \mathrm{c}, \mathrm{C}\left(\mathrm{CH}_{3}\right)_{2}\right), 3.49\left(8 \mathrm{H}, \mathrm{m}^{3} J_{\mathrm{HH}}=13.7, \mathrm{CH}_{2}\right)$, 7.20 (8Н, уш.м, СН), 7.35 (4H, уш.м, СН), $7.88\left(2 \mathrm{H}\right.$, д $^{3} J_{\mathrm{HН}}=7.4$, $\left.\mathrm{CH}^{4,5}\right) .{ }^{31}$ Р ЯМР $\left(1,4-\right.$-диоксан) $\delta_{\mathrm{p}}$ м.д.: 66.7.

1,9-Бис(диэтиламидо)-1,9-дитион-13,13-дигидро3,4,5,6,7-нафто-11,12;14,15-ди (1,2-нафто)-2,8,10,16-тетраокси-1,9-дифосфочиклодекагексан (27). Выход 0.25 (34\%). Маслообразное вещество. $\mathrm{R}_{f} 0.75$ (А), 0.65 (B). ${ }^{1} \mathrm{H}$ ЯМР $\delta_{\mathrm{H}}$ м.д.: $1.30\left(12 \mathrm{H}\right.$, т, $\left.\mathrm{CH}_{3}\right), 3.38\left(8 \mathrm{H}, \mathrm{m}^{3} J_{\mathrm{PH}}=12.8, \mathrm{CH}_{2}\right), 4.45(1 \mathrm{H}$, д $\left.{ }^{2} J_{\mathrm{HH}}=16.1, \mathrm{CH}_{2 \text { (мост) }}\right), 5.32\left(1 \mathrm{H}\right.$, д $\left.^{2} J_{\mathrm{Hн}}=16.1, \mathrm{CH}_{2 \text { (мост) }}\right), 7.17(2 \mathrm{H}$, д, $\left.\mathrm{CH}^{1,8}\right), 7.22\left(2 \mathrm{H}\right.$, д $\left.^{3} J_{\mathrm{HH}}=8.9, \mathrm{CH}^{3^{\prime}, 3^{\prime \prime}}\right), 7.40-7.68\left(10 \mathrm{H}, \mathrm{м}, \mathrm{CH}^{3,6,4^{4}, 4^{\prime \prime}}\right.$ $\left., 5^{5}, 5^{\prime \prime}, 6^{\prime}, 6^{\prime \prime}, 7^{\prime}, 7^{\prime \prime}\right), 7.82\left(2 \mathrm{H}\right.$, д, $\left.\mathrm{CH}^{4,5}\right), 8.38\left(2 \mathrm{H}\right.$, д $\left.^{3} \mathrm{HH}_{\mathrm{HH}}=8.4, \mathrm{CH}^{8,}, 8^{8 \prime}\right) .{ }^{31} \mathrm{P}$

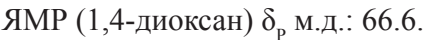

Окисление (общая методика). К раствору 1 ммоль циклофосфита (5 a-d, 14-19) в 4 мл сухого метиленхлорида при комнатной температуре и постоянном перемешивании добавляли 0,2 г гидроперита. Через сутки реакционную массу фильтровали, растворитель упаривали до 1 мл и высаждали циклоамидофосфаты (28a-d, 29-33) гексаном, а фосфат 34 хроматографировали на колонке, элюируя системой хлороформ-метанол, 10:1. Полученные продукты сушили в вакууме 2 ч ( $\left.70^{\circ} \mathrm{C}, 1 \mathrm{Topp}\right)$.

Цикло[бис(2,7-нафтилендиметиламидофосфат)] (28a). Выход 0,47 г (96\%). T $192-193{ }^{\circ} \mathrm{C} . \mathrm{R}_{f} 0.72(\mathrm{E}) .{ }^{1} \mathrm{H}$ ЯМР $\delta_{\mathrm{H}}$ м.д.: $2.97\left(12 \mathrm{H}\right.$, д $\left.{ }^{3} J_{\mathrm{PH}}=9.9, \mathrm{CH}_{3}\right), 7.49\left(4 \mathrm{H}\right.$, д $\left.{ }^{3} J_{\mathrm{Hн}}=8.4, \mathrm{CH}^{3,6}\right)$, $7.80\left(4 \mathrm{H}, \mathrm{c}, \mathrm{CH}^{1,8}\right), 7.92\left(4 \mathrm{H}\right.$, д $\left.^{3} J_{\mathrm{HH}}=8.4, \mathrm{CH}^{4,5}\right) .{ }^{31} \mathrm{P}$ ЯMP $\left(\mathrm{CH}_{2} \mathrm{Cl}_{2}\right)$

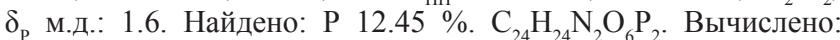
P $12.43 \%$.

Цикло[бис(2,7-нафтилендиэтиламидофосфат)] (28b). Выход 0,52 г (93\%). $\mathrm{T}_{\text {п }} 131-132{ }^{\circ} \mathrm{C} . \mathrm{R}_{f} 0.65(\mathrm{E}) .{ }^{1} \mathrm{H}$ ЯМР $\delta_{\mathrm{H}}$ м.д.: $1.17\left(12 \mathrm{H}, \mathrm{T}^{3} J_{\mathrm{HH}}=6.6, \mathrm{CH}_{3}\right), 3.39\left(8 \mathrm{H}, \mathrm{m}^{3} J_{\mathrm{PH}}=11.8, \mathrm{CH}_{2}\right), 7.49(4 \mathrm{H}$, д $\left.^{3} J_{\mathrm{HH}}=8.0, \mathrm{CH}^{3,6}\right), 7.80\left(4 \mathrm{H}, \mathrm{c}, \mathrm{CH}^{1,8}\right), 7.92\left(4 \mathrm{H}\right.$, д $\left.^{3} J_{\mathrm{HH}}=8.1, \mathrm{CH}^{4,5}\right)$. ${ }^{31} \mathrm{P}$ ЯМР $\left(\mathrm{CH}_{2} \mathrm{Cl}_{2}\right) \delta_{\mathrm{P}}$ м.Д.: 1.2. Найдено: Р $11.20 \% . \mathrm{C}_{28} \mathrm{H}_{32} \mathrm{~N}_{2} \mathrm{O}_{6} \mathrm{P}_{2}$. Вычислено: Р $11.17 \%$.

Цикло[бис(2,7-нафтиленпиперидиламидофосфат)] (28d). Выход 0,51 г (88\%). Маслообразное вещество. $\mathrm{R}_{f} 0.61$ (Е). ${ }^{1} \mathrm{H}$ ЯМР $\delta_{\mathrm{H}}$ м.д.: $1.48\left(12 \mathrm{H}, \mathrm{м}, \mathrm{CH}_{2}\right), 3.30\left(8 \mathrm{H}, \mathrm{m}^{3} J_{\mathrm{PH}}=7.3\right.$, $\left.\mathrm{CH}_{2}\right), 7.04-7.70(12 \mathrm{H}$, уш.м, $\mathrm{CH}) .{ }^{31} \mathrm{P}$ ЯМР $\left(\mathrm{CH}_{2} \mathrm{Cl}_{2}\right) \delta_{\mathrm{p}}$ м.д.: 0.8 .

Цикло[(1,7-нафтилен)-(2,7-нафтилен)-бис (диэтиламидофосфат)] (29). Выход 0,51 г (92\%). Маслообразное вещество. $\mathrm{R}_{f} 0.79(\mathrm{E}){ }^{1} \mathrm{H}$ ЯМР $\delta_{\mathrm{H}}$ м.д.: $1.04\left(12 \mathrm{H}\right.$, уш.т ${ }^{3} J_{\mathrm{HH}}=7.0$, $\left.\mathrm{CH}_{3}\right), 3.29-3.38$ (8H, уш.м, $\left.\mathrm{CH}_{2}\right), 7.33-8.09$ (12H, уш.м, $\left.\mathrm{CH}\right)$.

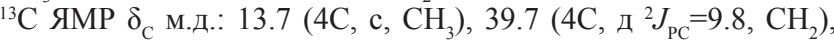
$110.7\left(1 \mathrm{C}\right.$, д $\left.^{3} J_{\mathrm{PC}}=6.6, \mathrm{C}^{2} \mathrm{H}\right), 115.4\left(1 \mathrm{C}\right.$, д $\left.^{3} J_{\mathrm{PC}}=5.9, \mathrm{C}^{8} \mathrm{H}\right), 116.1(2 \mathrm{C}$, д $\left.{ }^{3} J_{\mathrm{PC}}=6.0, \mathrm{C}^{1^{\prime}, 8^{8}} \mathrm{H}\right), 119.8\left(2 \mathrm{C}\right.$, д $\left.^{3} J_{\mathrm{PC}}=6.5, \mathrm{C}^{3}, 6^{\prime} \mathrm{H}\right), 121.1(1 \mathrm{C}, \mathrm{c}$, $\left.\mathrm{C}^{6} \mathrm{H}\right), 124.1\left(1 \mathrm{C}, \mathrm{c}, \mathrm{C}^{4} \mathrm{H}\right), 125.0\left(1 \mathrm{C}, \mathrm{c}, \mathrm{C}^{5} \mathrm{H}\right), 126.8\left(1 \mathrm{C}, \mathrm{c}, \mathrm{C}^{3} \mathrm{H}\right)$, $129.5\left(1 \mathrm{C}, \mathrm{c}, \mathrm{C}^{4}, 5^{\prime} \mathrm{H}\right), 129.8\left(1 \mathrm{C}, \mathrm{c}, \mathrm{C}^{9}\right), 131.9\left(1 \mathrm{C}, \mathrm{c}, \mathrm{C}^{10^{0}}\right), 134.6$ $\left(1 \mathrm{C}, \mathrm{c}, \mathrm{C}^{9,10}\right), 146.6\left(1 \mathrm{C}\right.$, д $\left.^{2} J_{\mathrm{PC}}=11.0, \mathrm{C}^{1} \mathrm{O}\right), 149.1$ ( $1 \mathrm{C}$, д $^{2} J_{\mathrm{PC}}=10.8$, $\left.\mathrm{C}^{7} \mathrm{O}\right), 149.2\left(2 \mathrm{C}\right.$, д $\left.^{2} J_{\mathrm{PC}}=10.2, \mathrm{C}^{2}, 7{ }^{\prime} \mathrm{O}\right) .{ }^{31} \mathrm{P}$ ЯМР $\left(\mathrm{CH}_{2} \mathrm{Cl}_{2}\right) \delta_{\mathrm{p}}$ м.д.: 1.0. Найдено: Р $11.29 \%$. $\mathrm{C}_{28} \mathrm{H}_{32} \mathrm{~N}_{2} \mathrm{O}_{6} \mathrm{P}_{2}$ Вычислено: $\mathrm{P} 11.17 \%$.

Цикло[(1,6-нафтилен)-(2,7-нафтилен)-бис (диэтиламидофосфат) (30). Выход 0,52 г (93\%). $\mathrm{T}$ 123-124 ${ }^{\circ} \mathrm{C} . \mathrm{R}_{f} 0.81$ (Е). ${ }^{1} \mathrm{H}$ ЯМР $\delta_{\mathrm{H}}$ м.д.: $1.03\left(12 \mathrm{H},{ }^{3} J_{\mathrm{HH}}=5.4, \mathrm{CH}_{3}\right), 3.27(8 \mathrm{H}, \mathrm{m}$ $\left.{ }^{3} J_{\mathrm{PH}}=11.8, \mathrm{CH}_{2}\right), 7.38\left(1 \mathrm{H}\right.$, дд $\left.{ }^{3} J_{\mathrm{Hн}}=9.9, \mathrm{CH}^{7}\right), 7.41\left(1 \mathrm{H}\right.$, д $^{3} J_{\mathrm{Hн}}=8.1$, $\left.\mathrm{CH}^{2}\right), 7.49\left(1 \mathrm{H},{ }^{3} \mathrm{~J}_{\mathrm{HH}}=8.1, \mathrm{CH}^{3}\right), 7.57\left(3 \mathrm{H}\right.$, уш.с, $\left.\mathrm{CH}^{5,1^{1}, 8^{8}}\right), 7.71$ $\left(1 \mathrm{H}\right.$, д $\left.{ }^{3} J_{\mathrm{Hн}}=7.8, \mathrm{CH}^{4}\right), 7.73\left(2 \mathrm{H}\right.$, д $\left.^{3} \mathrm{HH}_{\mathrm{Hн}}=8.5, \mathrm{CH}^{3,}, 6^{\prime}\right), 7.76(2 \mathrm{H}$, д $\left.{ }^{3} J_{\mathrm{HH}}=8.5, \mathrm{CH}^{4^{\prime}, 5^{7}}\right), 8.09\left(1 \mathrm{H}\right.$, д $\left.^{3} J_{\mathrm{HH}}=9.9, \mathrm{CH}^{8}\right) .{ }^{31} \mathrm{P}$ ЯMP $\left(\mathrm{CH}_{2} \mathrm{Cl}_{2}\right) \delta_{\mathrm{P}}$ 
м.д.: 1.2. Найдено: С 60.59, Н 5.80, N 5.10, Р $11.18 \%$. $\mathrm{C}_{28} \mathrm{H}_{32} \mathrm{~N}_{2} \mathrm{O}_{6}$. Вычислено: С 60.64, Н 5.82, N 5.05, Р 11.17 \%.

Цикло[(1,5-нафтилен)-(2,7-нафтилен)-бис(диэтиламидофосфат)] (31). Выход 0,52 г (93\%). $\mathrm{T}_{\text {пл }} 92-93^{\circ} \mathrm{C} . \mathrm{R}_{f} 0.84$ (Е). ${ }^{1} \mathrm{H}$ ЯМР $\delta_{\mathrm{H}}$ м.д.: $1.04\left(12 \mathrm{H},{ }^{3} \mathrm{~J}_{\mathrm{HH}}=7.4, \mathrm{CH}_{3}\right), 3.29(8 \mathrm{H}, \mathrm{м}$ $\left.{ }^{3} J_{\mathrm{PH}}=9.3, \mathrm{CH}_{2}\right), 7.25\left(2 \mathrm{H}\right.$, д, $\left.{ }^{3} J_{\mathrm{HH}}=8.7, \mathrm{CH}^{3}, 6^{\circ}\right), 7.27\left(2 \mathrm{H}\right.$, д $^{3} J_{\mathrm{HH}}=6.9$, $\left.\mathrm{CH}^{2,6}\right), 7.39\left(2 \mathrm{H}, \mathrm{T}^{3} J_{\mathrm{HH}}=8.8, \mathrm{CH}^{3,7}\right), 7.68\left(2 \mathrm{H}, \mathrm{c}, \mathrm{CH}^{1,8}\right), 7.75(2 \mathrm{H}$, д $\left.^{3} \mathrm{HH}_{\mathrm{HH}}=8.7, \mathrm{CH}^{4,5^{\prime}}\right), 7.87\left(2 \mathrm{H}\right.$, д $\left.^{3} \mathrm{HH}_{\mathrm{HH}}=8.8, \mathrm{CH}^{4,8}\right) .{ }^{31} \mathrm{P}$ ЯMP $\left(\mathrm{CH}_{2} \mathrm{Cl}_{2}\right)$ $\delta_{\mathrm{p}}$ м.д.: 1.3. Найдено: С 60.68, Н 5.73, N 5.15, Р $11.21 \% . \mathrm{m} / z$ (MALDI) 554.29. $\mathrm{C}_{28} \mathrm{H}_{32} \mathrm{~N}_{2} \mathrm{O}_{6} \mathrm{P}_{2}$. Вычислено: С 60.64, Н 5.82, N $5.05, \mathrm{P} 11.17 \%$. M 554.18.

Цикло[(2,6-нафтилен)-(2,7-нафтилен)-бис(диэтиламидофосфат)] (32). Выход 0,5 г (91\%). $\mathrm{T}_{\text {пл }} 126-127^{\circ} \mathrm{C} . \mathrm{R}_{f} 0.54$ (D), 0.82 (Е). ${ }^{1} \mathrm{H}$ ЯМР $\delta_{\mathrm{H}}$ м.д.: $1.06\left(12 \mathrm{H}, \mathrm{T}^{3} J_{\mathrm{HН}}=7.2, \mathrm{CH}_{3}\right), 3.27$ $\left(8 \mathrm{H}, \mathrm{M}^{3} J_{\mathrm{PH}}=8.9, \mathrm{CH}_{2}\right), 7.37\left(2 \mathrm{H}\right.$, д $\left.^{3} J_{\mathrm{HH}}=8.9, \mathrm{CH}^{3}, 6^{6}\right), 7.44(2 \mathrm{H}$, д $\left.{ }^{3} J_{\mathrm{HH}}=8.8, \mathrm{CH}^{3,7}\right), 7.67$ (4H, уш.с, $\left.\mathrm{CH}^{1,8^{7}, 1,5}\right), 7.74\left(2 \mathrm{H}\right.$, д $^{3} J_{\mathrm{HH}}=8.8$, $\left.\mathrm{CH}^{4,8}\right), 7.79\left(2 \mathrm{H}\right.$, д $\left.^{3} \mathrm{JH}_{\mathrm{HН}}=8.9, \mathrm{CH}^{4,5}\right) .{ }^{31} \mathrm{P}$ ЯMР $\left(\mathrm{CH}_{2} \mathrm{Cl}_{2}\right) \delta_{\mathrm{P}}$ м.д.: 1.2 . Найдено: Р $11.19 \%$. $\mathrm{C}_{28} \mathrm{H}_{32} \mathrm{~N}_{2} \mathrm{O}_{6} \mathrm{P}_{2}$. Вычислено: Р $11.17 \%$.

1,9-Бис(диэтиламидо)-1,9-диоксо-15,15-диметил3, 4,5,6,7-нафто-11,12,13,14;16,17,18,19-дибензо-2,8,10,20тетраокси-1,9-дифосфоциклоэйкозан (33). Выход 0,33 г (54\%). Маслообразное вещество. $\mathrm{R}_{f} 0.66$ (D). ${ }^{1} \mathrm{H}$ ЯМР $\delta_{\mathrm{H}}$ м.д.: $1.06\left(12 \mathrm{H}, \mathrm{T}{ }^{3} J_{\mathrm{HH}}=7.5, \mathrm{CH}_{3}\right), 1.57\left(6 \mathrm{H}, \mathrm{c}, \mathrm{C}\left(\mathrm{CH}_{3}\right)_{2}\right), 3.27(8 \mathrm{H}, \mathrm{m}$ $\left.{ }^{3} J_{\mathrm{HН}}=11.6, \mathrm{CH}_{2}\right), 7.15\left(8 \mathrm{H}\right.$, уш.м $\left.{ }^{3} J_{\mathrm{Hн}}=8.2, \mathrm{CH}^{\mathrm{A}, \mathrm{B}}\right), 7.38(6 \mathrm{H}$, д $\left.{ }^{3} J_{\mathrm{HH}}=8.8, \mathrm{CH}^{3}, 6^{\prime}\right), 7.61\left(2 \mathrm{H}, \mathrm{c}, \mathrm{CH}^{1}, 8^{\prime}\right), 7.87\left(2 \mathrm{H}\right.$, д $\left.^{3} J_{\mathrm{HH}}=8.8, \mathrm{CH}^{4^{\prime}, 5^{\prime}}\right)$. ${ }^{31} \mathrm{P}$ ЯMP $\left(\mathrm{CH}_{2} \mathrm{Cl}_{2}\right) \delta_{\mathrm{p}}$ м.д.: 1.1 .

1,9-Диэтиламидо-1,9-диоксо-13,13-дигидро-3, 4, 5, 6, 7нафто-11,12;14,15-ди-(1,2-нафто)-2,8,10,16-тетраокси-1,9дифосфоииклодекагексан (34). Выход 0,59 г (85\%). T п 149-150 ${ }^{\circ} \mathrm{C} . \mathrm{R}_{f} 0.56$ (А). ${ }^{1} \mathrm{H}$ ЯМР $\delta_{\mathrm{H}}$ м.д.: $1.31\left(12 \mathrm{H}, \mathrm{T}^{3} \mathrm{~J}_{\mathrm{HН}}=7.0, \mathrm{CH}_{3}\right), 3.33$ $\left(8 \mathrm{H}, \mathrm{M}^{3} J_{\mathrm{PH}}=12.8, \mathrm{CH}_{2}\right), 4.94\left(1 \mathrm{H}\right.$, д $\left.^{2} J_{\mathrm{HH}}=16.2, \mathrm{CH}_{2 \text { (мост })}\right), 5.16(1 \mathrm{H}$, д $\left.{ }^{2} J_{\mathrm{HH}}=16.2, \mathrm{CH}_{2(\text { мост) }}\right), 7.21\left(2 \mathrm{H}\right.$, д $\left.^{3} J_{\mathrm{HH}}=9.2, \mathrm{CH}^{1,8}\right), 7.31(2 \mathrm{H}$, д, $\left.\mathrm{CH}^{3,3 "}\right), 7.39\left(2 \mathrm{H}, \mathrm{c}, \mathrm{CH}^{6,6^{\prime \prime}}\right), 7.44\left(2 \mathrm{H}, \mathrm{M}^{3} J_{\mathrm{HH}}=7.9,{ }^{4} J_{\mathrm{HH}}=1.2, \mathrm{CH}^{3,6}\right)$, $7.54\left(2 \mathrm{H}, \mathrm{м}^{3} J_{\mathrm{HH}}=7.6,{ }^{4} J_{\mathrm{HH}}=1.2, \mathrm{CH}^{7,7}\right), 7.67$ ( $2 \mathrm{H}$, д, $\left.\mathrm{CH}^{4,4}{ }^{\prime \prime}\right), 7.73$ $\left(2 \mathrm{H}\right.$, д $\left.^{3} J_{\mathrm{Hн}}=8.9, \mathrm{CH}^{4,5}\right), 7.82\left(2 \mathrm{H}\right.$, д $\left.^{3} J_{\mathrm{Hн}}=7.6, \mathrm{CH}^{5,5}\right), 8.30(2 \mathrm{H}$, д $\left.{ }^{3} J_{\mathrm{HH}}=8.2, \mathrm{CH}^{8,8}\right) .{ }^{13} \mathrm{C}$ ЯМР $\delta_{\mathrm{C}}$ м.д.: $13.9\left(4 \mathrm{C}\right.$, д $\left.^{3} \mathrm{JC}_{\mathrm{PC}}=20.7, \mathrm{CH}_{3}\right)$, $23.9\left(1 \mathrm{C}, \mathrm{c}, \mathrm{CH}_{2 \text { (мост }}\right), 39.9\left(4 \mathrm{C}\right.$, д $\left.^{2} J_{\mathrm{PC}}=24.2, \mathrm{CH}_{2}\right), 109.9(2 \mathrm{C}, \mathrm{c}$,

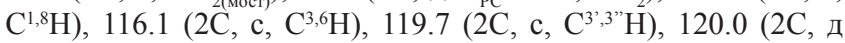
$\left.{ }^{3} J_{\mathrm{PC}}=5.2, \mathrm{C}^{1,}, \mathrm{l}^{\prime \prime} \mathrm{H}\right), 123.3\left(2 \mathrm{C}, \mathrm{c}, \mathrm{C}^{4,}, 4^{\prime \prime} \mathrm{H}\right), 124.8\left(2 \mathrm{C}, \mathrm{c}, \mathrm{C}^{5,}, 5^{\prime \prime} \mathrm{H}\right), 127.0$ $\left(2 \mathrm{C}, \mathrm{c}, \mathrm{C}^{7}, 7^{\prime \prime} \mathrm{H}\right), 127.9\left(1 \mathrm{C}, \mathrm{c}, \mathrm{C}^{10}\right), 128.7$ (4C, c, $\left.\mathrm{C}^{6,7}, \mathrm{C}^{7}, 7^{7} \mathrm{H}\right), 129.2$ (2C, c, $\left.\mathrm{C}^{10^{\prime}, 10^{\prime \prime}}\right), 129.5\left(2 \mathrm{C}, \mathrm{c}, \mathrm{C}^{4,5} \mathrm{H}\right), 132.6$ (2C, c, $\left.\mathrm{C}^{9^{\prime}, 9^{\prime \prime}}\right), 134.5$ (1C, c, $\left.\mathrm{C}^{9}\right), 149.1$ (2С, д, $\mathrm{C}^{2}, 2$, O $), 149.6\left(2 \mathrm{C}\right.$, д $\left.^{3} J_{\mathrm{PC}}=9.5, \mathrm{C}^{2,7} \mathrm{O}\right) .{ }^{31} \mathrm{P}$ ЯMP

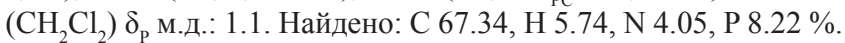
$m / z$ (MALDI) 694.15. $\mathrm{C}_{39} \mathrm{H}_{40} \mathrm{~N}_{2} \mathrm{O}_{6} \mathrm{P}_{2}$. Вычислено: С 67.43, Н 5.80, N 4.03, P 8.92 \%. M 694.69.

2,7-Бис(7-гидроксинафтилен-2-диэтиламидотионфосфатокси)нафталин (36). К 0,62 г (2,5 ммоль) ГЭТА $2 \mathbf{b}$ при комнатной температуре и постоянном перемешивании добавляли 0,2 г (1,25 ммоль) 2,7-дигидроксинафталина 1 в 5 мл ацетонитрила. Через 15 мин в реакционную смесь вводили еще 1,2 г (7,5 ммоль) нафтодиола (1) в 7 мл ацетонитрила и перемешивали еще 3 ч. Затем добавляли 0,08 г (2,5 ммоль) серы и оставляли на сутки. После этого растворитель отгоняли в вакууме, а остаток хроматографировали на колонке, элюируя полученный продукт системой бензол-диоксан, $7: 1$. Полученный продукт сушили в вакууме 2 ч (70 ${ }^{\circ} \mathrm{C}, 1$ Торр). Выход 0,39 г (32\%). Маслообразное вещество. $\mathrm{R}_{f} 0.51$ (А). ${ }^{1} \mathrm{H}$ ЯМР $\delta_{\mathrm{H}}$ м.д.: $1.19\left(12 \mathrm{H}, \mathrm{\text {т }}, \mathrm{CH}_{3}\right), 3.52\left(8 \mathrm{H}, \mathrm{M}^{3} \mathrm{~J}_{\mathrm{PH}}=12.8, \mathrm{CH}_{2}\right), 6.92$ (2H, уш.с, $\mathrm{OH}), 7.22,7.34$ (6H, д, $\mathrm{CH}), 7.52,7.56(6 \mathrm{H}, \mathrm{c}, \mathrm{CH})$, 7.78, $7.81(6 \mathrm{H}, \mathrm{м}, \mathrm{CH}) .{ }^{31} \mathrm{P}$ ЯМР $\left(\mathrm{CH}_{3} \mathrm{CN}\right) \delta_{\mathrm{p}}$ м.д.: 67.3. Найдено: С 61.00, Н 5.36, N 3.72, Р 8.23 \%. $\mathrm{C}_{38} \mathrm{H}_{40} \mathrm{~N}_{2} \mathrm{O}_{6} \mathrm{P}_{2} \mathrm{~S}_{2}$ Вычислено: С 61.11, H 5.40, N 3.75, P $8.29 \%$.

Цикло[трис(2,7-нафтилен)-бис(диэтиламидофосфитоксидиалкиламидотионфосфат)] (38). Метод 1. К 2 ммоль (2a,b) в 7 мл ацетонитрила при комнатной температуре и перемешивании добавляли 1,52 г (2 ммоль) соединения 36 и выдерживали 1 сут. Образовавшийся маслообразный осадок промывали ацетонитрилом, растворяли в 5 мл метиленхлорида и добавляли 0,064 г (2 ммоль) серы. Через 1 сут раствор фильтровали, фильтрат упаривали в вакууме, остаток хроматографировали на колонке, элюируя продукты системой бензол-диоксан, $9: 1$ и сушили в вакууме 2 ч (50 ${ }^{\circ} \mathrm{C}, 1$ Торр). Метод 2. К 0,494 г (2 ммоль) ГЭТА 2b при комнатной температуре и перемешивании добавляли 0,16 г (1 ммоль) нафтодиола 1 в 6 мл ацетонитрила. Через 15 мин в реакционную смесь вводили 1 ммоль тионфосфата 40a,b. Реакционную смесь выдерживали 1 сут. Выпавший осадок промывали ацетонитрилом, растворяли в 5 мл метиленхлорида и добавляли 0,064 г (2 ммоль) серы. Через 10 часов раствор фильтровали, упаривали в вакууме, остаток очищали как в Методе 1.

Цикло-[трис(2,7-нафтилен)-бис (диэтиламидофосфитокси)(диметиламидотионфосфат)] (38a). Выход 0,53 Г (50\%). $\mathrm{T}_{\text {пл }} 108-109^{\circ} \mathrm{C} . \mathrm{R}_{f} 0.42(\mathrm{~A}) .{ }^{1} \mathrm{H}$ ЯМР $\delta_{\mathrm{H}}$ м.Д.: $1.19(12 \mathrm{H}$, т, $\left.\mathrm{CH}_{3}\right), 2.77\left(6 \mathrm{H}\right.$, д $\left.^{3} \mathrm{~J}_{\mathrm{PH}}=12.2, \mathrm{~N}-\mathrm{CH}_{3}\right), 3.17\left(8 \mathrm{H}, \mathrm{м}{ }^{3} \mathrm{JH}_{\mathrm{PH}}=13.8\right.$, $\left.\mathrm{CH}_{2}\right), 7.38\left(6 \mathrm{H}\right.$, д $\left.^{3} \mathrm{JH}_{\mathrm{HH}}=7.1, \mathrm{CH}^{3,6}\right), 7.63\left(6 \mathrm{H}, \mathrm{c}, \mathrm{CH}^{1,8}\right), 7.79(6 \mathrm{H}$, д $\left.{ }^{3} \mathrm{JH}_{\mathrm{HH}}=7.1, \mathrm{CH}^{4,5}\right) .{ }^{31} \mathrm{P}$ ЯMР $\left(\mathrm{CH}_{2} \mathrm{Cl}_{2}\right) \delta_{\mathrm{P}}$ м.д.: 66.9; 68.5. Найдено: $m / z$ (MALDI) 852.18. $\mathrm{C}_{36} \mathrm{H}_{36} \mathrm{~N}_{3} \mathrm{O}_{6} \mathrm{P}_{3} \mathrm{~S}_{3}$. Вычислено: $M 852.68$.

Цикло-\{трис[(2,7-нафтилен)(диэтиламидотионфосфат)]\} (38b). Выход 0,69 г (78\%). $\mathrm{T} \quad 93-94{ }^{\circ} \mathrm{C}$. $\mathrm{R}_{f} 0.79(\mathrm{~A}) .{ }^{1} \mathrm{H}$ ЯМР $\delta_{\mathrm{H}}$ м.д.: $1.16\left(18 \mathrm{H}, \mathrm{T}^{3} J_{\mathrm{Hн}}=6.8, \mathrm{CH}_{3}\right), 3.49$ $\left(12 \mathrm{H}, \mathrm{m}^{3} J_{\mathrm{PH}}=14.1, \mathrm{CH}_{2}\right), 7.35\left(6 \mathrm{H}\right.$, д $\left.^{3} J_{\mathrm{HH}}=8.5, \mathrm{CH}^{3,6}\right), 7.63(6 \mathrm{H}, \mathrm{c}$, $\left.\mathrm{CH}^{1,8}\right), 7.79\left(6 \mathrm{H}\right.$, д $\left.^{3} J_{\text {нн }}=8.5, \mathrm{CH}^{4,5}\right) .{ }^{31} \mathrm{P}$ ЯMP $\left(\mathrm{CH}_{2} \mathrm{Cl}_{2}\right) \delta_{\mathrm{p}}$ м.д.: 67.2. Найдено: С 57.32, Н 5.49, N 4.78, Р $10.56 \%$. $\mathrm{C}_{42} \mathrm{H}_{48} \mathrm{~N}_{3} \mathrm{O}_{6} \mathrm{P}_{3} \mathrm{~S}_{3}$. Вычислено: С 57.34, Н 5.5, N 4.76, Р $10.52 \%$.

О,О-Бис(7-гидроксинафтилен-2-ол)диалкиламидо-

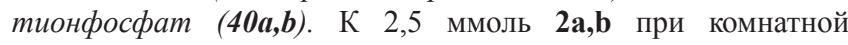
температуре и постоянном перемешивании добавляли 1,2 г (7,5 ммоль) нафтодиола (1) и выдерживали в течение 3 ч. Затем в реакционную смесь вводили 0,08 г (2.5 ммоль) серы и выдерживали еще 3 ч. После этого раствор фильтровали, упаривали в вакууме, а остаток хроматографировали на колонке, элюируя продукт 40a системой бензол-диоксан, $7: 1$, продукт 40b системой бензол-диоксан, 9:1. Полученные вещества сушили в вакууме 2 ч $\left(60^{\circ} \mathrm{C}, 1\right.$ Торр).

О,О-Бис(7-гидроксинафтилен-2-ол)диметиламидотионфосфат (40a). Выход 0,21 г (50\%). $\mathrm{T}_{\text {пा }} 108-109^{\circ} \mathrm{C} . \mathrm{R}_{f} 0.41$ (А). ${ }^{1} \mathrm{H}$ ЯМР $\delta_{\mathrm{H}}$ м.д.: $3.02\left(6 \mathrm{H}\right.$, д $\left.^{3} J_{\mathrm{PH}}=12.1, \mathrm{CH}_{3}\right), 6.00(2 \mathrm{H}$, уш.с, $\mathrm{OH}), 7.00\left(2 \mathrm{H}\right.$, дд $\left.{ }^{3} J_{\mathrm{Hн}}=8.8,{ }^{4} J_{\mathrm{Hн}}=2.2, \mathrm{CH}^{3,3^{\prime}}\right), 7.03\left(2 \mathrm{H}, \mathrm{c}, \mathrm{CH}^{1,1^{\prime}}\right)$, $7.22\left(2 \mathrm{H}\right.$, дд $\left.{ }^{3} \mathrm{~J}_{\mathrm{Hн}}=8.8,{ }^{4} \mathrm{~J}_{\mathrm{Hн}}=1.7, \mathrm{CH}^{6,6}\right), 7.48\left(2 \mathrm{H}\right.$, д ${ }^{4} \mathrm{~J}_{\mathrm{Hн}}=2.2$, $\left.\mathrm{CH}^{8,8^{\prime}}\right), 7.63\left(2 \mathrm{H}\right.$, д $\left.^{3} J_{\mathrm{HH}}=8.8, \mathrm{CH}^{4,4^{\prime}}\right), 7.70\left(6 \mathrm{H}\right.$, д $\left.^{3} \mathrm{HH}_{\mathrm{HH}}=8.8, \mathrm{CH}^{5,5^{\prime}}\right)$. ${ }^{31} \mathrm{P}$ ЯMР $\left(\mathrm{CH}_{3} \mathrm{CN}\right) \delta_{\mathrm{p}}$ м.д.: 68.5

О,О-Бис(7-гидроксинафтилен-2-ил)диэтиламидотионфосфат (40b). Выход 0,28 г (62\%). $\mathrm{T}_{\text {пл }} 112-113{ }^{\circ} \mathrm{C} . \mathrm{R}_{f} 0.48$ (A), 0.72 (Е). ${ }^{1} \mathrm{H}$ ЯМР $\delta_{\mathrm{H}}$ м.д.: $1.19\left(6 \mathrm{H}, \mathrm{T}^{3}{ }^{\mathrm{HH}}=7.0, \mathrm{CH}_{3}\right), 3.53$ $\left(4 \mathrm{H},{ }^{3}{ }^{3} J_{\mathrm{PH}}=14.0, \mathrm{CH}_{2}\right), 7.00\left(2 \mathrm{H}\right.$, дд $\left.{ }^{3} J_{\mathrm{HH}}=8.9,{ }^{4} J_{\mathrm{HH}}=2.2, \mathrm{CH}^{3,3^{\prime}}\right)$, $7.05\left(2 \mathrm{H}, \mathrm{c}, \mathrm{CH}^{1,1^{\prime}}\right), 7.24\left(2 \mathrm{H}\right.$, дд $\left.{ }^{3} J_{\mathrm{Hн}}=8.8,{ }^{4} J_{\mathrm{HH}}=1.7, \mathrm{CH}^{6,6^{6}}\right), 7.51$ $\left(2 \mathrm{H}\right.$, д $\left.{ }^{4} \mathrm{JH}_{\mathrm{HH}}=2.2, \mathrm{CH}^{8,8^{\prime}}\right), 7.66\left(2 \mathrm{H}\right.$, д $\left.^{3} \mathrm{~J}_{\mathrm{HH}}=8.9, \mathrm{CH}^{4,4^{\prime}}\right), 7.72(6 \mathrm{H}$, д $\left.{ }^{3} J_{\mathrm{HH}}=8.8, \mathrm{CH}^{5,5^{\prime}}\right), 7.40(2 \mathrm{H}$, уш.с, $\mathrm{OH}) .{ }^{31} \mathrm{P}$ ЯMP $\left(\mathrm{CH}_{3} \mathrm{CN}\right) \delta_{\mathrm{P}}$ м.д.: 66.9. Найдено: С 63.56, Н 5.33, N 3.08, P $6.84 \%$. $\mathrm{C}_{24} \mathrm{H}_{24} \mathrm{~N}_{1} \mathrm{O}_{4} \mathrm{P}_{1} \mathrm{~S}_{1}$. Вычислено: С 63.58, Н 5.31, N 3.04, Р $6.85 \%$.

Цикло[тетра(2,7-нафтилендиэтиламидофосфит)] (42). Смесь 3.08 г (12.5 ммоль) амида $2 \mathbf{b}$ и 1 г (6.2 ммоль) нафтодиола 1 в 30 мл безводного ацетонитрила перемешивали при комнатной температуре 15 мин, после чего добавляли 2.98 г (18.6 ммоль) нафтодиола 1 в 15 мл безводного ацетонитрила и перемешивали 4 ч. Затем в реакционную смесь вводили 3.08 г (12,5 ммоль) амида $\mathbf{2 b}$ и выдерживали еще 24 ч. Выпавшее масло отделяли от реакционного раствора, промывали ацетонитрилом и небольшими порциями экстрагировали соединение $\mathbf{4 2}$ гексаном. Гексановый раствор упаривали в вакууме, а остаток сушили 2 ч $\left(50{ }^{\circ} \mathrm{C}, 1\right.$ Торр). Выход 5,55 г (85\%). T $81-83{ }^{\circ} \mathrm{C}$. $\mathrm{R}_{f} 0.71$ (D). ${ }^{1} \mathrm{H}$ ЯМР $\delta_{\mathrm{H}}$ м.д.: $1.08\left(24 \mathrm{H}, \mathrm{T}^{3}{ }^{3} \mathrm{HH}=7.2, \mathrm{CH}_{3}\right), 3.29$ $\left(16 \mathrm{H}, \mathrm{m}^{3} J_{\mathrm{PH}}=10.5, \mathrm{CH}_{2}\right), 7.16\left(8 \mathrm{H}\right.$, д $\left.^{3} \mathrm{HH}_{\mathrm{HH}}=8.5, \mathrm{CH}^{3,6}\right), 7.35(8 \mathrm{H}$, 
c, $\left.\mathrm{CH}^{1,8}\right), 7.70\left(8 \mathrm{H}\right.$, д $\left.^{3} \mathrm{HH}_{\mathrm{HH}}=8.9, \mathrm{CH}^{4,5}\right) .{ }^{31} \mathrm{P}$ ЯMP $\left(\mathrm{CH}_{2} \mathrm{Cl}_{2}\right) \delta_{\mathrm{p}}$ м.д.: 138.7. Найдено: С 64.40, Н 6.19, N 5.38, P 11.89 \%. m/z (MALDI) 1044.37. $\mathrm{C}_{56} \mathrm{H}_{64} \mathrm{~N}_{4} \mathrm{O}_{8} \mathrm{P}_{4}$. Вычислено: С 64.36, Н 6.17, N 5.36, Р 11.86 \%. M 1044.37.

Цикло[тетра(2,7-нафтилендиэтиламидтионфосфат)] (43). К раствору 0,31 г (0,3 ммоль) фосфита 42 в 5 мл метиленхлорида добавляли 0,048 г (1,5 ммоль) серы. Реакционную смесь выдерживали при комнатной температуре в течение суток. Раствор упаривали до минимума, а остаток хроматографировали на колонке, элюируя соединение 45 хлороформом. Остаток после упаривания растворителя обрабатывали ацетоном, фильтровали от избытка серы, упаривали и сушили в вакууме 2 ч $\left(50^{\circ} \mathrm{C}, 1 \mathrm{Topp}\right)$. Выход 0,26 Г (75\%). $\mathrm{T}_{\text {пл }} 218-220{ }^{\circ} \mathrm{C} . \mathrm{R}_{f} 0.52(\mathrm{~A}) .{ }^{1} \mathrm{H}$ ЯМР $\delta_{\mathrm{H}}$ м.д.: $1.16(24 \mathrm{H}$, т $\left.{ }^{3} J_{\mathrm{HH}}=6.6, \mathrm{CH}_{3}\right), 3.50\left(16 \mathrm{H}, \mathrm{m}^{3} J_{\mathrm{PH}}=13.6\right.$ Гц $\left.\mathrm{CH}_{2}\right), 7.35(8 \mathrm{H}$, д $\left.{ }^{3} J_{\mathrm{HH}}=8.6, \mathrm{CH}^{3,6}\right), 7.62\left(8 \mathrm{H}, \mathrm{c}, \mathrm{CH}^{1,8}\right), 7.77\left(8 \mathrm{H}\right.$, д $\left.^{3} J_{\mathrm{HH}}=8.7, \mathrm{CH}^{4,5}\right)$. ${ }^{31} \mathrm{P}$ ЯМР $\left(\mathrm{CH}_{2} \mathrm{Cl}_{2}\right) \delta_{\mathrm{p}}$ м.д.: 67.0 .

Цикло[тетра(2,7-нафтилендиэтиламидфосфат] (44). К раствору 0,31 г (0,3 ммоль) фосфита 42 в 7 мл метиленхлорида добавляли 0,03 г (0,3 ммоль) (30\% избыток) гидроперита и выдерживали при комнатной температуре в течение 24 ч. Раствор фильтровали, упаривали до минимума и высаждали фосфат 44 гексаном, раствор декантировали, а осадок сушили в вакууме 2 ч $\left(50{ }^{\circ} \mathrm{C}, 1 \mathrm{Topp}\right)$. Выход 0,3 г (90\%). $\mathrm{T}_{\text {пи }} 224-226$ ${ }^{\circ} \mathrm{C} . \mathrm{R}_{f} 0.81$ (Е). ${ }^{1} \mathrm{H}$ ЯMР $\delta_{\mathrm{H}}$ М.д.: $1.04\left(24 \mathrm{H}\right.$, т, $\left.\mathrm{CH}_{3}\right), 3.26(16 \mathrm{H}$, м $\left.{ }^{3} J_{\mathrm{PH}}=12.0, \mathrm{CH}_{2}\right), 7.36\left(8 \mathrm{H}\right.$, д $\left.{ }^{3} J_{\mathrm{HH}}=8.8, \mathrm{CH}^{3,6}\right), 7.67(8 \mathrm{H}, \mathrm{c}$, $\left.\mathrm{CH}^{1,8}\right), 7.78\left(8 \mathrm{H}\right.$, д $\left.^{3} J_{\mathrm{HH}}=8.7, \mathrm{CH}^{4,5}\right) .{ }^{31} \mathrm{P}$ ЯМР $\left(\mathrm{CH}_{2} \mathrm{Cl}_{2}\right) \delta_{\mathrm{P}}$ м.д.: 1.2. Найдено: С 60.80, Н 5.78, N 5.00, Р $11.22 \%$. $\mathrm{C}_{56} \mathrm{H}_{64} \mathrm{~N}_{4} \mathrm{O}_{12} \mathrm{P}_{4}$. Вычислено: С 60.65, Н 5.82, N 5.05, Р 11.17 \%.

Рентгеноструктурные исследования. Данные PCA получены на автоматическом дифрактометре CAD-4 с $\mathrm{MoK} / \alpha$ излучателем. Структуры решены прямым методом и уточнены полноматричным методом наименьших квадратов в анизотропном приближении.

Кристалл соединения $\mathbf{4 b}$ моноклинный $\left(\mathrm{C}_{26} \mathrm{H}_{46} \mathrm{~N}_{4} \mathrm{O}_{2} \mathrm{P}_{2} \mathrm{~S}_{2}\right.$, $M=572.73)$, размеры $0.33 \times 0.20 \times 0.15$ мм, специальная группа $\mathrm{P} 2(1) / \mathrm{C}, \mathrm{a}=14.177(3) \AA, \mathrm{в}=18.133(4) \AA, \mathrm{c}=13.414(3) \AA, \alpha=$ $90^{\circ}, \beta=110.63(3)^{\circ}, \gamma=90^{\circ}, \mathrm{V}=3227.2(12) \AA^{3}, d_{\text {выч }} 1.179 \mathrm{мг} /$ $\mathrm{M}^{3}, \mu=0.292 \mathrm{Mм}^{-1} \cdot F(000)=1232$. В расчетах участвовало 1757 независимых отражений с I $>2 \sigma(1)$. Окончательное значение факторов расходимости $\mathrm{R}_{1}=0.0675, \mathrm{wR}_{2}=0.1738$.

\section{Список литературы}

\section{References}

1. Diederich F. Cyclophanes. Cambridge: Royal Society of Chemistry, 1991. 313 p.

2. Steed W.J., Atwood J.L. Supramolecular Chemistry. John Wiley \& Sons, Ltd, 2000. 772 p.

3. Böckmann K., Vögtle F. Chem. Ber. 1981, 114, 1065-1073.

4. Mitchel R.H., Weerawarna K., Buschnell G.W. Tetrahedron Lett. 1984, 25, 907-910.

5. Sato T., Matsui H., Komaki R. J. Chem. Soc. Perkin Trans. I 1976, 2051-2054.

6. Sakurai H., Hoshi S., Kamiua A., Hosomi A., Kabuto C. Chem. Lett. 1986, 1781-1783.

7. Kira M., Tokura S. Organometallics 1997, 16, 1100-1102.

8. Rezzonico B., Grignon-Dubois M., Laguerre M., Leger J.-M. Organometallics 1998, 17, 2656-2664.
9. Croux S., Maurette M.-T., Hocquaux M., Ananides A., Braun A.M., Oliveros E. New. J. Chem. 1990, 14, 161-167.

10. Soltermann A.T., Luiz M., Biasutti M.A., Carrascoso M., AmatGuerri F., Garcia N.A. J. Photochem. Photobiol., A 1999, 129 , 25-32.

11. Andrews D.D., Beddard G.S. J. Phys. Chem. A 2000, 104, 7785-7792.

12. Simpson T.J., Bandumathie Weerassoriya M.K. J. Chem. Soc. Perkin Trans. I 2000, 2771-2775.

13. Schwabacher A.W., Shuhong Z., William D. J. Am. Chem. Soc. 1993, 115, 6995-6996.

14. Amany Ibrachim M.A. Can. J. Anal. Sci. Specrosc. 1999, 44, 1-9.

15. Tamaka A., Fujiyoshi S., Motomura K., Hayashida O., Hisaeda Y., Murakami Y. Tetrahedron 1998, 54, 5187-5206.

16. Benson D.R., Fu J., Johnson C.K., Pauls S.W., Williamson D.R. J. Org. Chem. 1998, 63, 9935-9945.

17. Hamilton A.D., Pant N., Muehldorf A. Pure Appl. Chem. 1988, $60,533-538$

18. Thisayukta J., Nakayama Y., Kawauchi S., Takezoe H., Watanabe J. J. Am. Chem. Soc. 2000, 122, 7441-7448.

19. Amaranatha Reddy R., Sadashiva B.K. J. Mater. Chem. 2004, 14, 1936-1947.

20. Eskelinen A., Molitor C., Kanerva L. Contact Dermatitis 1997, $36,312-316$.

21. Bloom C.R., Heymann R., Kaarsholm N.C., Dunn M.F. Biochemistry 1997, 36, 12746-12758.

22. Yan H.-Q., Chen S., Qi G.-R. Polymer 2003, 44, 7861-7867.

23. Watson W.H., Nagl A., Ednok E. Acta Cryst. 1989, 45, 303306.

24. Anibarro M., Geszler K., Uson I., Sheldrick G.M., Saenger W. Carbohydr. Res. 2001, 333, 251-256.

25. Rozycka-Sokolowska E., Marciniak B., Pavlycka V. Acta Cryst. 2005, 61, 114-115.

26. Nifantiev E.E., Gratchev M.K., Burmistrov S.Yu. Chem. Rev. 2000, 100, 3755-3799.

27. Slitikov P.V., Nifantyev E.E., Rasadkina E.N., Vasyanina L.K. Phosphorus, Sulfur Silicon Relat. Elem. 2005, 180, 513-526.

28. Slitikov P.V., Rasadkina E.N., Nifant'ev E.E. Russ. J. Gen. Chem. 2006, 76, 183-197.

29. Nifantyev E.E., Rasadkina E.N., Batalova T.A. Dokl. Akad. Nauk 1997, 353, 350-353 (in Russ.).

30. Danilova O.I., Arshinova R.P., Ovodova O.V., Arbuzov B.A. Zh. Obshch. Khim. 1987, 57, 2679-2688 (in Russ.).

31. Nifantyev E.E., Rasadkina E.N., Evdokimova Yu.B., Stash A.I., Belsky V.K., Vasyanina L.K. Heteroat. Chem. 2003, 14, 404412.

32. Bauer I., Habicher W.D., Jones P.G., Thönnessen H., Schmutzler R. Phosphorus, Sulfur Silicon Relat. Elem. 1998, 143, 19-31.

33. Allinger N.L. J. Am. Chem. Soc. 1977, 99, 8127-8134.

34. Nifantyev E.E., Rasadkina E.N., Yankovich I.V., Vasyanina L.K., Belsky V.K., Stash A.I. Heteroat. Chem. 1998, 9, 643-649.

35. Nifant'ev E.E., Rasadkina E.N., Yankovich I.V., Vasyanina L.K., Belsky V.K., Stash A.I. Russ. J. Gen. Chem. 1999, 69, 32-38.

36. Nifant'ev E.E., Rasadkina E.N., Maslennikova V.I. Russ. J. Gen. Chem. 1999, 69, 1736-1757.

37. Noth H., Vetter H.J. Chem. Ber. 1965, 98, 1981-1987.

38. Stuebe C., Lankelma H.P. J. Am. Chem. Soc. 1956, 78, 976-977.

39. Burgada R. Ann. Chim. 1963, 8, 351-370. 